\title{
Modeling spatial patterns of saturated areas: An evaluation of different terrain indices
}

\author{
Andreas Güntner \\ GeoForschungsZentrum Potsdam (GFZ), Potsdam, Germany \\ Jan Seibert \\ Department of Environmental Assessment, Swedish University of Agricultural Sciences, Uppsala, Sweden
}

Stefan Uhlenbrook

Institute of Hydrology, University of Freiburg, Freiburg, Germany

Received 7 November 2003; revised 11 March 2004; accepted 25 March 2004; published 25 May 2004.

[1] A key component to understanding and predicting water fluxes and water quality in river basins is the spatial distribution of water-saturated areas. There is limited knowledge on spatial patterns of saturated areas, their relation to landscape characteristics and processes, and the ability of hydrological models to represent the observed spatial patterns, particularly at the large scales most relevant for water resources management. In this study, saturated areas were mapped in two mesoscale $\left(18\right.$ and $\left.40 \mathrm{~km}^{2}\right)$, humid temperate basins. Geobotanical and pedological criteria were used to achieve a consistent time-integrated delineation of saturated areas. Using commonly available spatial data on landscape characteristics, various terrain indices were evaluated for their ability to predict the observed patterns. Quantitative performance criteria describing the agreement of modeled and observed spatial patterns included cell-by-cell and cell-neighborhood approaches. Upslope contributing area was the most important single factor explaining the observed pattern. An improved pattern was obtained for the topographic wetness index (TOPMODEL index). However, the performance was markedly sensitive to the algorithms used for calculation of upslope contributing area and slope gradient. Other factors such as soil or climate were of less value for improving the predictions. The optimum spatial agreement of observed and modeled saturated areas was about $50 \%$ for a combined soil-climate-topographic index. Geological features (bedrock fractures) partly explained the residual pattern. Using an independent test catchment, it was shown that the index approach can be transferred to basins with similar physiographic characteristics for estimating the general pattern of saturated areas. INDEX TERMS: 1866 Hydrology: Soil moisture; 1860 Hydrology: Runoff and streamflow; KEYWORDS: saturated area, mesoscale, spatial pattern, terrain index, pattern comparison

Citation: Güntner, A., J. Seibert, and S. Uhlenbrook (2004), Modeling spatial patterns of saturated areas: An evaluation of different terrain indices, Water Resour. Res., 40, W05114, doi:10.1029/2003WR002864.

\section{Introduction}

[2] Saturated areas have a major influence on a range of hydrological processes such as runoff processes and flooding [e.g., Dunne and Black, 1970], solute transport [e.g., Curmi et al., 1998], and land-atmosphere interactions [e.g., Quinn and Beven, 1993; Entekhabi et al., 1996], as well as pedogenic and geomorphological processes [e.g., Beven and Kirkby, 1993]. To quantify catchment responses, i.e., water fluxes and water quality, a definition of major hydrological processes within a catchment including their location and spatial extent is crucial. Saturation excess runoff, which is different in hydrochemistry and runoff dynamics from other runoff components generated in the basin, has been observed to be an important runoff component in many humid catchments

Copyright 2004 by the American Geophysical Union. 0043-1397/04/2003WR002864\$09.00 [e.g., Anderson and Burt, 1990]. Thus the spatial and often time-variable delineation of saturated areas is a key to understanding and predicting catchment responses.

[3] The location of saturated areas can be estimated using detailed, highly parameterized approaches that model all governing processes defining the distribution of soil moisture in space and time, but this approach is impractical because of data limitations and a lack of understanding of the governing processes at scales from plots to catchments. Progress has recently been made in mapping saturated areas by remote sensing [e.g., Troch et al., 2001], but there remain problems with pixel resolution and the difficulty to distinguish the signal of surface saturated areas from other signals. An alternative method is the use of terrain indices as an attempt to derive soil moisture patterns directly from landscape characteristics thought to correlate with the dominant factors of process control [e.g., Kirkby, 1975; Western et al., 1999]. As wet areas were often found to be associated with 
topographic depressions and flat areas, the indices focus on topographic measures as a first-order control of soil moisture [Kirkby, 1975; Beven and Kirkby, 1979; O'Loughlin, 1986]. They are often based on widely available digital elevation models (DEM) and are easy to calculate using a geographic information system (GIS). However, the manner in which topographic information is explored varies for the different indices. Various topographic attributes such as surface slope, upslope area, curvature, or combinations of these primary attributes can be used. Additionally, index values may vary depending on the algorithm used for the calculations. For instance, algorithms for calculating the upslope area differ with regard to the treatment of topographic sinks and channel initiation, or with regard to the assignment of flow directions within the generalized representation of the real topography in a DEM [e.g., Quinn et al., 1995]. Barling et al. [1994] developed a wetness index with a time-variable contributing upslope area that can be smaller than the area derived from DEM analysis.

[4] Some terrain indices account for factors other than topography that may influence soil moisture patterns, notably soil characteristics [Beven, 1986] or available energy from solar radiation [Moore et al., 1991; Gómez-Plaza et al., 2001]. However, a more complex index does not necessarily ensure better predictions of soil moisture status. The seasonal variability of dominant process control on soil moisture status and wetness patterns [Grayson et al., 1997; Western et al., 1999; Williams et al., 2003] adds an additional complexity to the application of terrain indices. Other possible causes of wet areas such as land use, mass movements (landslides), geology and tectonics, as well as anthropogenic influences are often not well understood or surveyed, particularly at larger scales, and are therefore difficult to parameterize and include in a terrain index.

[5] Different terrain indices and different calculation algorithms as a tool for the prediction of saturated areas or soil moisture patterns have not been analyzed extensively, particularly not for larger areas. Only a few studies have investigated the predictive power of terrain indices by comparing estimated and observed patterns on larger areas (e.g., that of Rodhe and Seibert [1999], who used the spatial distribution of wetlands to validate the prediction of the TOPMODEL wetness index), and most studies concentrate on small areas of about $1 \mathrm{~km}^{2}$ or less [Beven and Kirkby, 1979; Burt and Butcher, 1985; Moore et al., 1988; Nyberg, 1996; Ambroise et al., 1996; Gineste et al., 1998; Western et al., 1999; Blazkova et al., 2002; Williams et al., 2003], mainly because of the limited availability of suitable data at larger scales. On the basis of the studies at small scales, it is difficult to assess the ability of terrain indices to predict soil moisture patterns at the landscape scale. Here additional factors such as variable water balance and higher spatial heterogeneity come into play. An extended assessment of the predictive power of terrain indices beyond the experimental catchment scale is, however, required as hydrological models for the river basin scale use these indices to account for smaller-scale soil moisture variability with the benefit of keeping a comparatively simple model structure and parameterization (e.g., TOPMODEL [Beven and Kirkby, 1979] and SEWAB [Mengelkamp et al., 2001]). In addition, for setting up process-oriented catchment models that require the delineation of zones of different dominating runoff processes as in the model of Uhlenbrook et al. [2004b], a modeling strategy is crucial to avoid time consuming mapping when transferring the model to other basins [Scherrer and Naef, 2003; Uhlenbrook, 2003]. In this context, the extended assessment of terrain indices is of great interest because the indices have the potential to contribute to delineating, e.g., the zones of saturation-excess runoff. In general, it has frequently been emphasized during recent years that the validation of spatial patterns against observations is a key issue for assessing model capabilities and uncertainties and for model improvements, even for practical applications in larger river basins [e.g., Refsgaard, 2001]. Franks et al. [1998] and Blazkova et al. [2002] used patterns of saturated areas to constrain the uncertainty of model parameters.

[6] For pattern comparison in the context of hydrological applications, however, thus far only a few methods have been used in practice [Grayson and Blöschl, 2001]. Comparing observed versus simulated binary patterns (e.g., saturated/nonsaturated areas) may include the following approaches: (1) visual comparison; (2) comparison of landscape metrics that describe the spatial configuration of patterns, such as fragmentation, irregularity, or complexity of shape [e.g., Haines-Young and Chopping, 1996; Gustafson, 1998]; (3) cell-by-cell comparisons, for example, the Kappa measure [Cohen, 1960], which is frequently used in map comparison of categorical data [e.g., Pontius, 2000] (for the binary case, it may be reduced to a counting of cells that have a certain attribute, e.g., saturated area, in both the observed and simulated patterns); (4) extensions of the strict cell-by-cell comparisons, e.g., accounting for shifts in the location of patterns [Grayson and Blöschl, 2001] or accounting for the cell neighborhood [Constanza, 1989] due to uncertainty of location, for instance [Hagen, 2003]. However, no standard on which approaches should be used for pattern comparison in hydrological applications for a given question of interest, pattern type, and scale or resolution yet exists.

[7] The objective of this study was to evaluate the predictive power of different terrain indices for modeling spatial patterns of saturated areas in a mesoscale catchment $\left(40 \mathrm{~km}^{2}\right)$, a spatial scale that is relevant for water resources management. Therefore a mapping method for saturated areas was developed that was for this large scale. It was our objective to examine the relevance of topographic attributes as well as other terrain characteristics for explaining the observed saturated area patterns. For that purpose, widely available spatial data sets were used to define and apply combined terrain indices. To evaluate the agreement of the simulated and observed spatial patterns, different quantitative performance criteria were developed and their power for this type of pattern comparison was analyzed. In order to evaluate the spatial transferability of the index approach for prediction of saturated area patterns, the approach was also applied in a neighboring catchment $\left(18.4 \mathrm{~km}^{2}\right)$ with similar physiographic characteristics.

\section{Study Area and Data}

\subsection{Test Sites}

[8] The study was performed primarily in the mesoscale Brugga basin $\left(40 \mathrm{~km}^{2}\right)$. The neighboring Zastler basin 


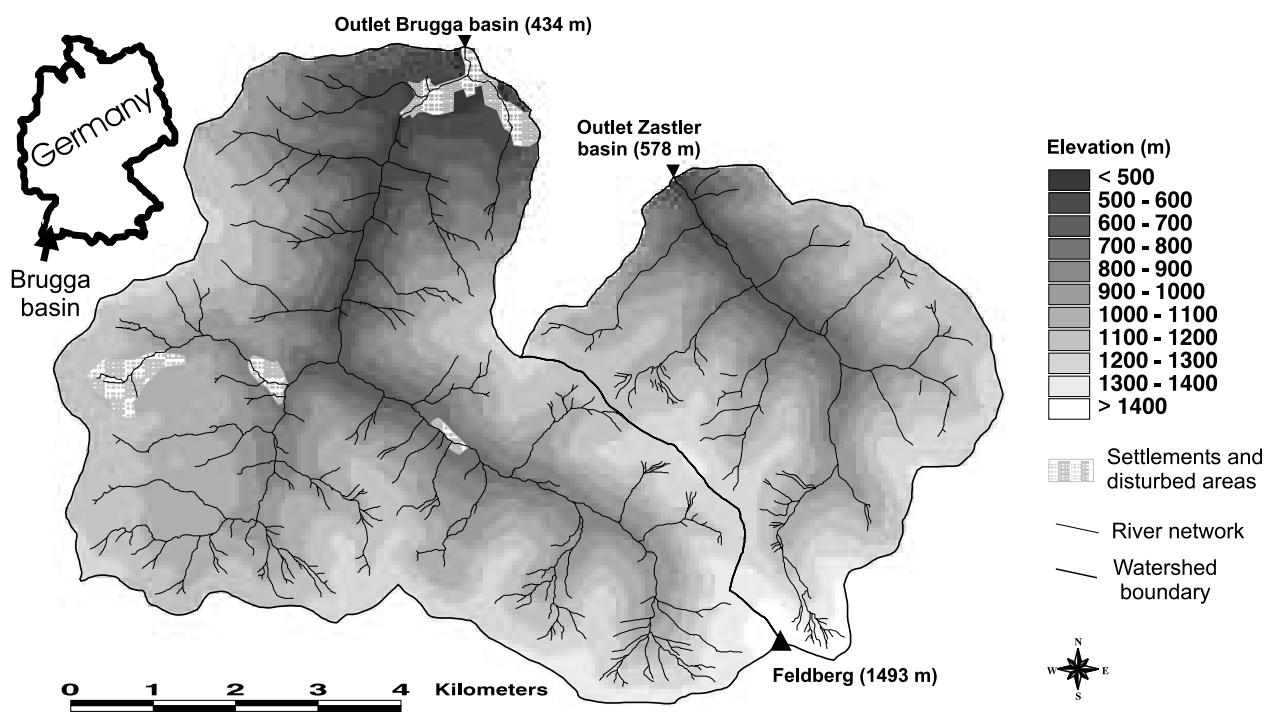

Figure 1. Location and topography of the Brugga and Zastler basins, southern Black Forest Mountains, southwest Germany.

$\left(18.4 \mathrm{~km}^{2}\right)$ was used as an additional site for testing the developed index modeling strategy. Both watersheds are located in the southern Black Forest Mountains in southwestern Germany (Figure 1). These are mountainous watersheds with elevation ranging from 438 to $1493 \mathrm{~m}$ above mean sea level and nival runoff regimes. The mean annual precipitation is approximately $1750 \mathrm{~mm}$ generating a mean annual discharge of approximately $1220 \mathrm{~mm}$ (values for the Brugga basin; there are only slight differences for the Zastler basin). The bedrock consists of gneiss, covered by weathering material of Pleistocene origin: debris, drift, and soils of varying depths $(0-10 \mathrm{~m})$. The basins are widely forested (approximately 75\%) and the remaining area is pasture. Urban land use is below $3 \%$.

[9] Preceding experimental studies including investigations with artificial and environmental tracers [Mehlhorn et al., 1998; Hoeg et al., 2002; Uhlenbrook et al., 2002] led to the following conceptual model of three main flow systems and of runoff generation in the Brugga and Zastler basin [Uhlenbrook et al., 2002]: (1) Fast runoff components (surface or near surface runoff) are generated on sealed or saturated areas and on steep highly permeable slopes covered by boulder fields. (2) Slow base flow components (deep groundwater) originate from the fractured hard rock aquifer and the deeper parts of the weathering zone. (3) An intermediate flow system contributes mainly from the (peri)glacial deposits of the hillslopes (shallow groundwater). This flow system predominates the storm discharge of larger floods. Springs draining such hillslopes can show remarkable short-term dynamics [Uhlenbrook et al., 2004a]. A spatial delineation of the Brugga and Zastler basins into areas of dominant runoff processes was performed [Uhlenbrook, 2003], based on surface characteristics as well as geological, pedological, and topographic information, a map of saturated areas [Güntner et al., 1999], and the analysis presented in this paper.

\subsection{Input Data Sets}

[10] The following spatial data sets were available: A forest habitat map (scale 1:10,000) covering the largest part of the forested area [Forstliche Versuchsanstalt (FVA),
1996]; geological maps (scale 1:50,000) [Geologisches Landesamt Baden-Württemberg (GLA), 1977]; a tectonic map giving the location of faults and fractures in the crystalline bedrock (scale 1:100,000) [GLA, 1981]; a coarse resolution soil map (scale 1:200,000) [Landesamt für Geologie, Rohstoffe und Bergbau Baden Württemberg, 1998]; and a digital elevation model (DEM) with a grid size of $50 \times 50 \mathrm{~m}^{2}$ (vertical resolution $0.1 \mathrm{~m}$ ) (Figure 1). In addition, a field survey was executed for mapping the saturated areas in both catchments (see below).

[11] On the basis of the DEM, the Brugga basin was classified into three main morphometric landscape units, i.e., hollows/channels, planes, and ridges. The classification was done with respect to local concavity or convexity of the terrain surface using the terrain analysis model LandSerf, version 1.8 [Wood, 1996, J. D. Wood, LandSerf: Visualisation and Analysis of Terrain Models, available at http:// www.soi.city.ac.uk/ jwo/landserf/]. Hollows or channels are located in areas of concavity, ridges in areas of convexity, and planes in areas without any significant local concavity or convexity. The fraction of the total Brugga basin area attributed to each of these three landscape units was approximately equal (Figures $2 \mathrm{a}$ and 5).

\subsection{Field Survey of Saturated Areas}

[12] Pedological and geobotanical mapping criteria were applied. Areas were mapped as saturated areas if they showed hydromorphic characteristics (i.e., gleyed soils with redox characteristics and high organic content in the topsoil or peat soils) in the entire soil profile. In addition, the mapped areas had to have a predominance of wetnessindicating plants as classified by Ellenberg [1991]. Indicator plants used in the study area were Aconitum napellus, Caltha palustris, Carex flava, Filipendula ulmaria, Juncus acutifloris, Juncus effusus, Myosotis palustris, Ranunculus flammula, Scirpus sylvaticus, and Viola palustris. Since these criteria were independent of the soil moisture conditions at the time of mapping, the procedure provided a long-term averaged pattern of the wettest zones in the basin.

[13] About $60 \%$ of the study area was mapped by the forest habitat survey $[F V A, 1996]$. The remaining area was 

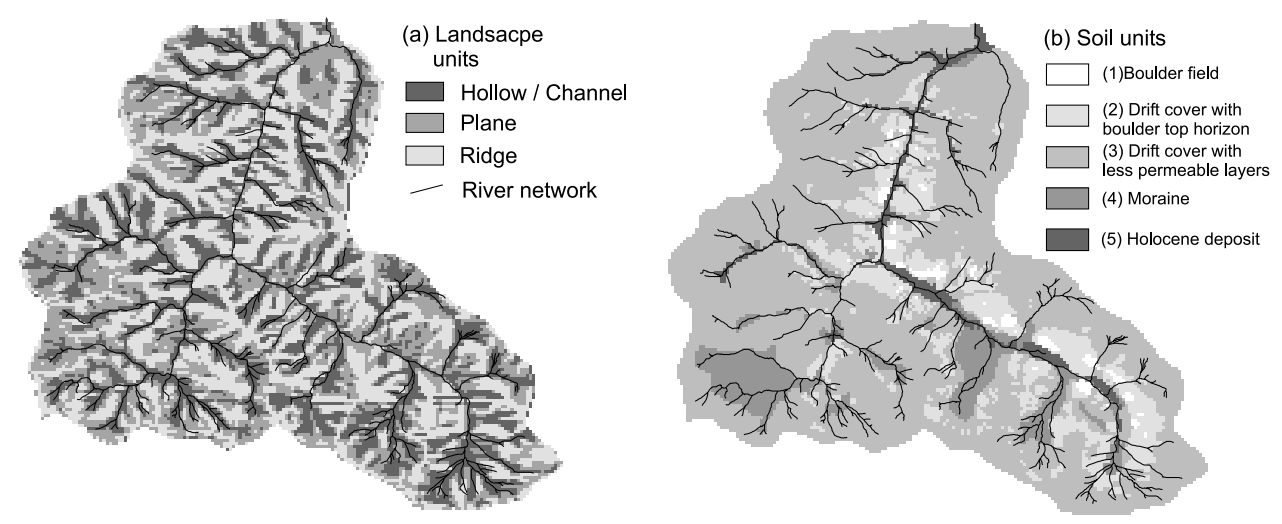

Figure 2. Spatial distribution of (a) landscape units and (b) soil units in the Brugga basin.

mapped in late summer (September and October) after a dry period. The resulting field maps (observation scale 1:5000) were digitized and transformed into a grid map with $10 \times 10 \mathrm{~m}^{2}$ cell resolution. This appeared to be an adequate resolution to preserve the small-scale structure of the observed saturated areas. It should be noted that the total extent of saturated areas on the digitized vector map and on the grid map was the same. In the next step, a $50 \times$ $50 \mathrm{~m}^{2}$ grid of saturated areas was generated, with resolution and location of the grid cells corresponding to the DEM. For each $50 \times 50 \mathrm{~m}^{2}$ grid cell, the areal fraction of saturated areas was calculated from the original vector map. Then, $50 \times 50 \mathrm{~m}^{2}$ cells were marked as saturated cells starting with the cell of the largest fraction of mapped saturated areas and continuing successively until the area of marked saturated cells matched the total extent of the mapped saturated area.

\section{Terrain Indices and Analysis Methods}

\subsection{Terrain Indices}

[14] For the derivation of spatial fields of terrain indices as predictors of saturated areas, primary terrain attributes as well as compound attributes that were combinations of primary attributes [Moore et al., 1991], were used (Table 1). All indices were calculated on a cell-by-cell basis for the $50 \times 50 \mathrm{~m}^{2}$ grid cells as defined by the DEM.

[15] Curvature (CURV) is a measure of the concavity or convexity of the terrain surface. It reflects changes in the hydraulic gradient along hillslopes and the convergence or divergence of flow pathways. Curvature for each cell was calculated as a combined tangent and profile curvature for a $3 \times 3$ cells window [Zevenbergen and Thorne, 1987; Moore et al., 1991] as implemented in the Geographic Information System ARC/INFO (Environmental Systems Research Institute (ESRI), Redlands, California).

[16] Three different algorithms for calculating the surface slope as a measure of the hydraulic gradient were tested: First, the slope for each cell was calculated after fitting a plane to the $3 \times 3$ cells neighborhood by an average maximum technique [Burrough, 1986] (mean slope, tan $\left.\beta_{3 \times 3}\right)$. This is a standard method included, for instance, in the GIS ARC/INFO. Second, the slope was derived as the average gradient between the cell of interest and all neighboring cells with lower elevation [Quinn et al., 1991] (local downhill slope, $\left.\tan \beta_{\text {local }}\right)$. Third, in contrast to these two methods that consider only the cells immediately adjacent to the cell of interest, the third method for slope calculations considered a larger downslope area. For each cell, the closest downslope cell with a previously defined elevation difference $d$ was determined. The distance $l$ to this cell (direct line between cell centers) was then used for slope calculation according to $\tan \beta_{d}=d / l$ [Hjerdt et al., 2004] (downslope index, $\tan \beta_{d}$ ). The reasoning behind this method is that it may better represent the groundwater table gradient because small-scale steps in surface topography not reflected in the groundwater surface are smoothed using tan $\beta_{d}$ due to the larger extent of included cells. Values for $d$ were set to $25 \mathrm{~m}\left(\tan \beta_{d=25}\right)$ and $10 \mathrm{~m}\left(\tan \beta_{d=10}\right)$.

[17] A radiation index (RAD), a simple measure of the influence of spatially varying evapotranspiration on soil moisture due to varying radiation energy, was calculated as the ratio $R_{i} / R_{\text {mean }} . R_{i}$ is the total annual solar radiation input to cell $i$, calculated with the Arc View GIS extension Solar Analyst (from Helios Environmental Modeling Institute HEMI, LLC, Los Alamos, New Mexico), taking slope, aspect, and shade effects by mountain ridges as the main influencing factors. $R_{\text {mean }}$ is the mean annual solar radiation input averaged for all cells of the study area.

[18] The upslope contributing watershed area (UCA) is a measure of the potential area that can deliver water via lateral flow pathways and thus influence the soil moisture status. It is assumed that the larger the contributing area, the larger the incoming accumulated flow volumes. For this index, flow directions between cells are to be established and a procedure corresponding to a "routing of area" between cells is required. Various methods for regular grid DEMs are presented in the literature [e.g., O'Callaghan and Mark, 1984; Freeman, 1991; Quinn et al., 1991, 1995; Lea, 1992; Costa-Cabral and Burges, 1994; Holmgren, 1994; Tarboton, 1997]. In this study, the portion $f_{i}$ of accumulated upslope area of one upslope cell attributed to each downslope cell $i$ was weighted with respect to the slope gradient $\tan \beta_{i}$ between the uplsope cell and cell $i$ relative to the slope gradients to all other downslope cells $j$ [Quinn et al., 1991] (equation (1)).

$$
f_{i}=\frac{\left(\tan \beta_{i}\right)^{h}}{\sum_{j=1}^{8}\left(\tan \beta_{j}\right)^{h}} \text { for all } \tan \beta_{j}>0
$$


As proposed by Freeman [1991] and Holmgren [1994], the strength of this weighting can be adjusted by an exponent $h$. For $h=1$, the index calculation corresponds to the multiple flow direction algorithm by Quinn et al. [1991]. For large values of $h$ (e.g., $h>15$ ) the computations approach those of the single flow direction algorithm where all the upslope area is routed to the cell in the steepest downslope direction [O'Callaghan and Mark, 1984].

[19] In the basic index calculation algorithms [e.g., Quinn et al., 1991], the accumulation of upslope contributing area occurs continuously down to the catchment outlet. Nevertheless, accumulated flow may enter a channel and be exported from the catchment without contributing to the development of saturated areas in downslope cells. Therefore a channel initiation threshold $\left(\mathrm{CIT}, \mathrm{m}^{2}\right)$, was used in the index calculations according to Quinn et al. [1995]. All cells with an upslope area exceeding CIT and the following downslope cells in the direction of the steepest gradient were marked as channel cells. The accumulated area of channel cells must not exceed CIT. The surplus of upslope area, i.e., accumulated flow volumes, is considered to contribute to the channel and is no longer accounted for in any downslope cell.

[20] The topography-based wetness index of Beven and Kirkby [1979] (TOPMODEL index, $T_{W I}$ ) was used as a combined index. It is calculated as a combination of the standardized upslope contributing area $a$ (standardized to the unit contour length), and the slope $\tan \beta$ as

$$
T_{W I}=\ln (a / \tan \beta)
$$

Different realizations of the TOPMODEL index with regard to the manner of determining the upslope contributing area and the slope value were applied in this study.

[21] Extending the purely topography-based terrain indices, a soil-topographic index, $T_{S W}$, as proposed by Beven [1986] was applied (equation (3)).

$$
T_{S W I}=\ln (a /(T \tan \beta))
$$

It accounts for the influence of varying soil transmissivity (for a saturated soil profile), $T$ in $\mathrm{m}^{2} \mathrm{~d}^{-1}$. On the basis of the very limited geological and pedological information (see data section) and on additional field experiments [Uhlenbrook et al., 2002], five different terrain units were distinguished for which markedly different soil characteristics could be assumed. Rough estimates of the order of magnitude of transmissivities for each soil unit were made, assuming an average soil depth to bedrock of $2 \mathrm{~m}$ [Hädrich et al., 1979], and hydraulic conductivities estimated from soil texture and artificial tracer tests [Mehlhorn et al., 1998] (Table 2 and Figure $2 \mathrm{~b}$ ). These $T$ values were used as starting values for the optimization of the soil-topographic index (see section 4.2).

[22] As a further extension of the (soil) topographic index, the spatial variability of the climatic water balance $C$ (rainfall minus evaporation in $\mathrm{mm}$ ) was taken into account as an additional measure that may influence the spatial pattern of soil moisture (climate- (soil) topographic index, $\left.T_{C W I}, T_{C S W I}\right)$. $C$ was derived by assuming a linear decrease of evaporation and an exponentially declining increase of precipitation with elevation as derived from climate station data for mean annual values [Uhlenbrook, 1999]. The basic grid size of each cell $s_{i}\left(=2500 \mathrm{~m}^{2}\right)$ was modified $\left(s_{i, \text { mod }}\right)$ as a function of the mean annual climatic water balance $C_{i}$ of the cell $i$ relative to the basin average $C_{m}$ (equation (4)). By this means, due to the "routing of area" as a simplified representation of the routing of water volumes in the topographic part of the index calculations, the effect of spatially varying climatic forcing among cells is captured for the downslope soil moisture status.

$$
s_{i, m o d}=s_{i} \frac{C_{i}}{C_{m}}
$$

We also tested the combination of $T_{W I}$ with different binary variables using logistic regression. These binary variables (see data section for the data sources) were (1) the neighborhood of tectonic faults and fractures, (2) location in a topographic depression, and (3) the occurrence of high or low soil conductivity. The logistic regression formula predicts the probability $p$ of the occurrence of saturated areas as a function of the independent variables $\left(x_{i}\right)$ (equation (5)). The parameters $b_{i}$ can be interpreted as odds ratios for the occurrence of saturated areas (i.e., the probability for "saturated" divided by the probability for "nonsaturated"). The value of $\exp \left(b_{i}\right)$ gives the relative amount by which the odds for "saturated" increase $(>1)$ or decrease $(<0)$ when the value of the independent variable is increased by one unit.

$$
p=\frac{\exp (y)}{1+\exp (y)}
$$

where

$$
y=b_{0}+\sum b_{i} x_{i}
$$

For comparison to the process-based terrain indices described above, a set of purely randomly distributed index patterns (RANDOM) was generated by attributing to each cell of the study area a random value between 0 and 1 , which was drawn from an uniformly distributed random variable.

\subsection{Performance Criteria}

[23] A variety of performance criteria were applied to evaluate the ability of different terrain indices to represent the spatial pattern of observed saturated areas (see also Table 3 for an overview and the optimum value for each criterion).

[24] 1. Criterion $k_{r a n k, 50}$ is the rank correlation coefficient (after Spearman) between terrain index values and the fraction of the observed saturated area on the total grid cell area for the $50 \times 50 \mathrm{~m}^{2}$ cells of the study area. Each grid cell was associated with two rank numbers: (1) the rank of the cell index value among all index values in the study area and (2) the rank of the mapped saturated area fraction on total cell area. 
Table 1. Overview of Tested Terrain Indices

\begin{tabular}{llll}
\hline Abbreviation & \multicolumn{1}{c}{ Index } & Type $^{\mathrm{a}}$ & \\
\hline CURV & curvature & 1 & Notes \\
$\tan \beta_{3 \times 3}$ & mean slope & 1 & gradient calculated from a $3 \times 3$ cell window \\
$\tan \beta_{\text {local }}$ & $\begin{array}{l}\text { local downhill slope } \\
\text { downslope index }\end{array}$ & 1 & $\begin{array}{l}\text { gradient to neighboring downslope cells } \\
\text { variations of the elevation difference } d \text { of } 10 \text { and } 25 \mathrm{~m} \text { (tan } \beta_{d=10} \text { and } \\
\text { tan } \beta_{\mathrm{d}}\end{array}$ \\
$\mathrm{RAD}$ & radiation index & 1 & \\
$\mathrm{UCA}$ & upslope contributing area & 1 & variations of Holmgren factor $h$ and channel initiation threshold CIT \\
$T_{W I}$ & TOPMODEL wetness index & 1 & combination of UCA and different slope indices \\
$T_{S W I}$ & soil-topographic index & 2 & combination of $T_{W I}$ and soil characteristics \\
$\mathrm{T}_{\mathrm{CWI}}, \mathrm{T}_{\mathrm{CSWI}}$ & climate-(soil) topographic index & 2 & combination of $T_{W I}$ or $T_{S W I}$ with climatic water balance \\
RANDOM & random index & 2 & random numbers between 0 and 1 \\
\hline
\end{tabular}

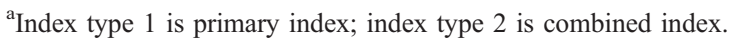

[25] 2. Criterion $k_{\text {rank,200 }}$ is the rank correlation coefficient (after Spearman) between terrain index values and the fraction of saturated area for aggregated $200 \times$ $200 \mathrm{~m}^{2}$ cells. The terrain index value for each $200 \times$ $200 \mathrm{~m}^{2}$ cell was calculated as the mean of all included $50 \times 50 \mathrm{~m}^{2}$ cells. This criterion was introduced to evaluate the correspondence of patterns at a coarser spatial resolution where local topographic smooth out to some extent.

[26] For further performance criteria, the basic principle was to select that subset of grid cells from each modeled index pattern that is most prone to surface saturation, i.e., the cells with the lowest or highest index values depending on the index definition. Starting with the cell with the lowest (or highest) value, all cells with successively larger (or lower) index values were selected until the fraction of the selected number of cells in the subset relative to the number of all cells in the study area was equal to the fraction of mapped saturated areas to total basin area. The resulting $50 \times 50 \mathrm{~m}^{2}$ cell pattern, M50, was disaggregated to a $10 \times 10 \mathrm{~m}^{2}$ grid resolution (pattern M10) by simply setting the cell value of each large cell of M50 to all 25 smaller cells in M10. The modeled patterns were then compared in the form of a binary variable (saturated/ nonsaturated) to the observed patterns both at the $50 \times$ $50 \mathrm{~m}^{2}$ (observed pattern O50) and the $10 \times 10 \mathrm{~m}^{2}$ grid resolution $(\mathrm{O} 10)$.

[27] 3. Criteria $k_{\text {match, } 10}$ and $k_{\text {match, } 50}$ are measures of the direct spatial coincidence of observed and modeled saturated areas for a cell-by-cell comparison, as percentage of the total saturated area (equations (6) and (7) and Figures 3a and $3 b$ ),

$$
\begin{aligned}
& k_{\text {match }, 10}=\frac{n_{10}^{+}}{n_{10}} 100 \\
& k_{\text {matc }, 50}=\frac{n_{50}^{+}}{n_{50}} 100
\end{aligned}
$$

where $n_{10}$ and $n_{50}$ give the total number of saturated grid cells in the study area for the $10 \mathrm{~m}$ and $50 \mathrm{~m}$ resolution grids, respectively; $n_{10}^{+}$is the number of spatially coinciding modeled and observed saturated areas in patterns M10 and $\mathrm{O} 10$; and $n_{50}^{+}$is the number of spatially coinciding modeled and observed saturated areas in patterns M50 and O50, respectively.

[28] 4. Criterion $k_{f u z z y}$ is a fuzzy criterion of spatial coincidence of observed and modeled saturated areas. Similar to the concept for map comparison presented by Hagen [2003], $k_{f u z z y}$ accounts for fuzziness of location, i.e., it accounts for modeled saturated areas that do not directly coincide with observed areas but that are close to them. The degree of coincidence is defined by a lower value if the distance between observed and modeled saturated cells is larger. This criterion considers that deviations in the location of observed and modeled saturated areas are also due to (1) the difference in the spatial resolution of modeling $(50 \mathrm{~m})$ and mapping (about $10 \mathrm{~m}$ ), (2) uncertainties of defining the exact position in the field, (3) errors in converting the

\begin{tabular}{|c|c|c|c|}
\hline Unit & Description & $T$ Estimated, $\mathrm{m}^{2} \mathrm{~d}^{-1}$ & $T$ Optimized, $\mathrm{m}^{2} \mathrm{~d}^{-1}$ \\
\hline 1 & $\begin{array}{l}\text { boulder fields, composed of highly permeable } \\
\text { material on steep slopes with large macropores }\end{array}$ & $1 \times 10^{4}$ & $1 \times 10^{3}$ \\
\hline 2 & $\begin{array}{l}\text { stratified periglacial drift cover on steeper slopes } \\
\text { with highly permeable boulder horizon as top layer }\end{array}$ & $1 \times 10^{3}$ & $1 \times 10^{3}$ \\
\hline 3 & $\begin{array}{l}\text { stratified periglacial drift cover on slopes and hilly uplands, } \\
\text { mainly sandy to loamy with varying content of coarse } \\
\text { fragments, including less permeable layers }\end{array}$ & $1 \times 10^{0}$ & $1 \times 10^{0}$ \\
\hline 4 & moraine material, loamy, often compacted & $1 \times 10^{-1}$ & $1 \times 10^{0}$ \\
\hline 5 & $\begin{array}{l}\text { Holocene deposits in the valley bottoms, mainly } \\
\text { loamy sand with varying content of coarse fragments }\end{array}$ & $1 \times 10^{1}$ & $5 \times 10^{0}$ \\
\hline
\end{tabular}

Table 2. Soil Units With Estimated and Optimized Transmissivity $T$ 

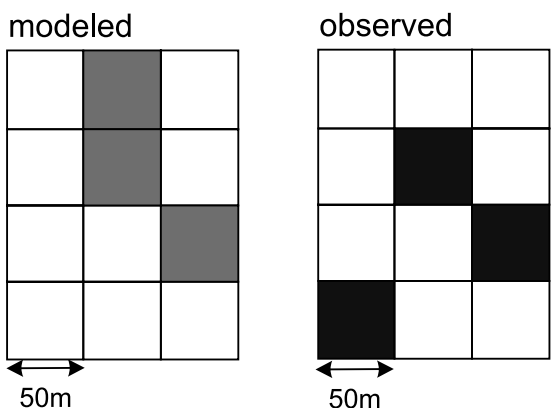

$50 \mathrm{~m}$

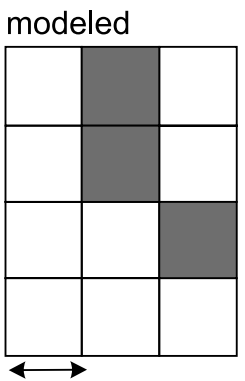

$50 \mathrm{~m}$

modeled

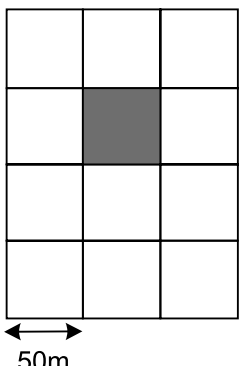

modeled

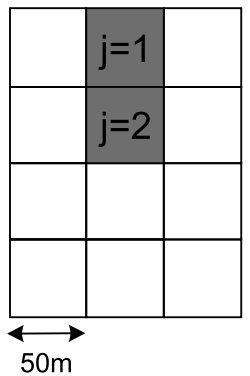

observed

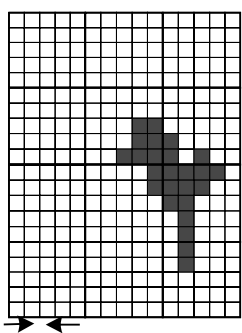

$10 \mathrm{~m}$

observed

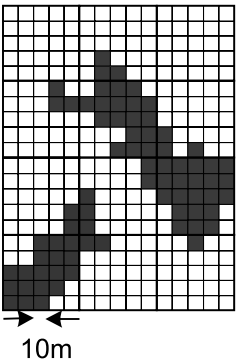

observed

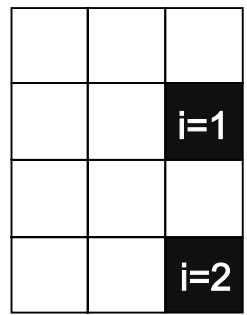

evaluation

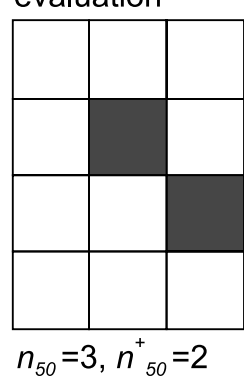

evaluation

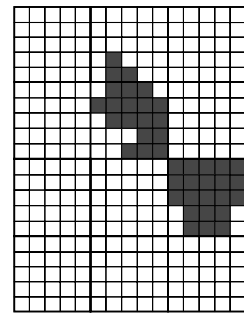

$n_{10}=70, n_{10}^{+}=41$

evaluation

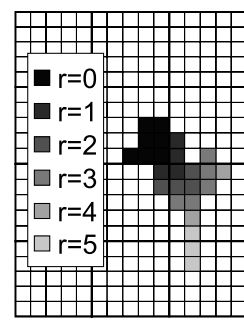

(a)

Criteria $\boldsymbol{k}_{\text {match, } 50}$ (c)

\section{Criteria $\boldsymbol{k}_{\text {fuzzy }}$}

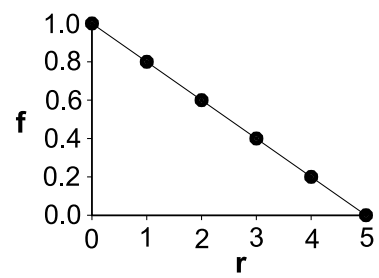

(b)

Criteria $\boldsymbol{k}_{\text {match, } 10}$

Figure 3. Exemplary explanation of the performance criteria, evaluating the agreement of modeled and observed patterns of saturated areas.

observations into a digital map, and (4) uncertainties in precisely delimiting the extent of saturated areas in the field. Through qualitative reasoning, a maximum tolerable distance between observations and model results for which some degree of correlation could still be assumed was set to about $50 \mathrm{~m}$. Accordingly, for an observed saturated cell $i$ being in a radius $r_{i}$ of 5 or more $10 \times 10 \mathrm{~m}^{2}$ cells distance away from any modeled cell, the degree of coincidence $f_{i}$ with the model was set to 0 . Other values of $f$ were defined according to equation (8) and Figure 3c.

$$
k_{f u z z y}=\frac{\sum_{i=1}^{n_{10}} f_{i}}{n_{10}} 100 \quad \text { with } f_{i}=1-0.2 r_{i}
$$

[29] 5. Criteria $k_{\text {dist,o }}$ and $k_{\text {dist }, m}$ are distance measures that describe the performance of the terrain indices as a function 
Table 3. Performance of Terrain Indices to Represent the Observed Pattern of Saturated Areas in the Brugga Basin

\begin{tabular}{|c|c|c|c|c|c|c|c|c|c|c|c|c|}
\hline & \multirow[b]{2}{*}{ CIT, ha } & \multirow[b]{2}{*}{$h$} & \multicolumn{10}{|c|}{ Criteria } \\
\hline & & & MPS, ha & MSI & $k_{\text {rank,50 }}$ & $k_{\text {rank, } 200}$ & $\begin{array}{c}k_{\text {match,10 }} \\
\%\end{array}$ & $\begin{array}{c}k_{\text {match, } 50} \\
\%\end{array}$ & $\begin{array}{c}k_{\text {fuzzy, }} \\
\%\end{array}$ & $\begin{array}{c}k_{\text {dist, o }}, \\
\mathrm{m}\end{array}$ & $\begin{array}{c}k_{\text {dist, } m}, \\
\mathrm{~m}\end{array}$ & $\frac{k_{\text {dist, mean }},}{\mathrm{m}}$ \\
\hline Perfect fit value & - & - & - & - & -1 or 1 & -1 or 1 & 100 & 100 & 100 & 0 & 0 & 0 \\
\hline Worst case value & - & - & - & - & 0 & 0 & 0 & 0 & 0 & $\infty$ & $\infty$ & $\infty$ \\
\hline \multicolumn{13}{|l|}{ Observed patterns } \\
\hline O10 (10 m grid) & - & - & 1.17 & 4.91 & - & - & - & - & - & - & - & - \\
\hline O50 (50 m grid) & - & - & 0.93 & 1.75 & - & - & - & - & - & - & - & - \\
\hline \multicolumn{13}{|l|}{ Random pattern } \\
\hline RANDOM & - & - & 0.32 & 1.12 & -0.004 & 0.001 & 6.5 & 6.1 & 20.5 & 101 & 182 & 142 \\
\hline \multicolumn{13}{|l|}{ Simple indices } \\
\hline RAD & - & - & 6.33 & 3.01 & -0.046 & 0.004 & 2.2 & 2.3 & 4.3 & 538 & 190 & 364 \\
\hline CURV & - & - & 1.45 & 2.01 & -0.341 & -0.432 & 16.4 & 16.3 & 27.3 & 196 & 118 & 157 \\
\hline $\tan \beta_{3 \times 3}$ & - & - & 2.06 & 2.33 & -0.226 & -0.269 & 12.1 & 11.9 & 19.5 & 248 & 195 & 222 \\
\hline $\tan \beta_{\text {local }}$ & - & - & 2.26 & 2.51 & -0.285 & -0.346 & 19.4 & 19.8 & 28.3 & 232 & 139 & 185 \\
\hline $\tan \beta_{d=10}$ & - & - & 2.55 & 2.77 & -0.261 & -0.313 & 22.6 & 22.4 & 29.3 & 296 & 118 & 207 \\
\hline $\tan \beta_{d=25}$ & - & - & 6.19 & 3.52 & -0.311 & -0.383 & 23.8 & 23.3 & 28.1 & 357 & 84 & 221 \\
\hline UCA & - & 1 & 12.65 & 11.95 & 0.403 & 0.489 & 27.4 & 26.6 & 36.1 & 228 & 86 & 157 \\
\hline UCA & - & 15 & 21.08 & 16.23 & 0.384 & 0.480 & 27.4 & 27.4 & 41.8 & 133 & 86 & 110 \\
\hline \multicolumn{13}{|l|}{ Combined indices } \\
\hline$T_{W I}$ with $\tan \beta_{3 \times 3}$ & - & 15 & 7.44 & 3.45 & 0.425 & 0.527 & 30.0 & 29.7 & 44.4 & 125 & 77 & 101 \\
\hline$T_{W I}$ with $\tan \beta_{d=25}$ & - & 15 & 7.23 & 9.79 & 0.432 & 0.535 & 30.3 & 30.0 & 44.2 & 132 & 75 & 104 \\
\hline$T_{W I}$ with $\tan \beta_{\text {local }}$ & - & 15 & 6.84 & 9.82 & 0.430 & 0.533 & 30.2 & 30.0 & 44.3 & 125 & 76 & 100 \\
\hline$T_{W I}$ with $\tan \beta_{\text {local }}$ & - & 1 & 7.23 & 7.47 & 0.441 & 0.540 & 31.0 & 30.1 & 41.0 & 211 & 75 & 143 \\
\hline$T_{W I}$ with $\tan \beta_{\text {local }}$ & 10 & 10 & 3.42 & 4.62 & 0.436 & 0.537 & 33.4 & 33.9 & 48.2 & 105 & 69 & 87 \\
\hline$T_{C W I}$ & 10 & 10 & 3.56 & 4.54 & 0.440 & 0.541 & 33.6 & 33.9 & 48.3 & 106 & 69 & 88 \\
\hline$T_{C S W I}$ & 10 & 10 & 3.16 & 2.88 & 0.404 & 0.473 & 31.0 & 30.9 & 41.9 & 179 & 66 & 122 \\
\hline best $T_{C S W I}$ & 8 & 8 & 2.53 & 3.19 & 0.426 & 0.491 & 34.2 & 34.0 & 50.7 & 92 & 66 & 79 \\
\hline Logistic regression & - & - & 3.24 & 3.71 & 0.436 & 0.568 & 33.5 & 33.1 & 49.2 & 105 & 69 & 87 \\
\hline
\end{tabular}

of the distance between observations and model results. The criteria are based on patterns O50 and M50 (see also Figure $3 \mathrm{~d}) . k_{\text {dist,o }}$ starts out from each observed saturated cell $i$ and looks for the closest modeled saturated grid cell $j$ to define the distance $d_{i j}$ as the straight line between the cell centers. $k_{\text {dist,o }}$ is the mean of these distances for all observed saturated cells (equation (9)). $k_{\text {dist, } m}$ reverses the point of view, starting out from each modeled saturated cell and looking for the distance $d_{j i}$ to the closest observed saturated cell (equation (10)). $k_{\text {dist,mean }}$ is used as a combined distance criteria (equation (11)).

$$
\begin{gathered}
k_{\text {dist }, o}=\frac{\sum_{i=1}^{n_{10}} d_{i j}}{n_{10}} \\
k_{\text {dist }, m}=\frac{\sum_{j=1}^{n_{10}} d_{j i}}{n_{10}} \\
k_{\text {dist,mean }}=\frac{\left(k_{\text {dist }, o}+k_{\text {dist }, m}\right)}{2}
\end{gathered}
$$

[30] In addition to the quantitative criteria presented above, the visual comparison of observed and modeled spatial patterns was used as qualitative information on match or mismatch of patterns. To support the visual description, two landscape metrics were used. (1) The first is mean patch size of saturated areas (MPS, $\mathrm{m}^{2}$ ). Grid cells marked as saturated area are considered to belong to the same patch if they are adjacent in at least one of eight grid directions, including the diagonals (eight-neighborhood rule). MPS is an indicator of pattern fragmentation. (2) The second is mean shape index (MSI, dimensionless). MSI is calculated according to equation (12) [Patton, 1975; Saura and Martínez-Millán, 2001]:

$$
\text { MSI }=\frac{\sum_{i=1}^{n_{p}} \frac{p_{i}}{4 \cdot \sqrt{a_{i}}}}{n_{p}}
$$

$n_{p}$ is the number of saturated patches in the study area, with a patch being defined as for MPS above. $p_{i}$ is the perimeter or total edge length of patch $i$ in $\mathrm{m}$, calculated as the sum of all side lengths that any grid cell of the patch $i$ shares with nonsaturated grid cells. $a_{i}$ is the size of patch $i$ in $\mathrm{m}^{2}$. MSI is a perimeter-area relationship that measures the irregularity in shape for saturated patches compared to a simple standard shape, i.e., a square in the raster representation. MSI is 1 if all saturated patches are squares and results in higher values with greater patch shape complexity.

\section{Results}

\subsection{Field Survey of Saturated Areas}

[31] In most locations, saturated areas could be clearly delimited in the field by the pedological and geobotanical criteria. Transitions to places with no wetness-indicating characteristics have often been observed within a very short distance $(<3 \mathrm{~m})$. In these cases, the extent of saturated areas was often constrained by steep slopes at their borders. Only a small number of saturated areas showed a more gradual transition into places with no wetness-indicating characteristics, e.g., in flatter sections of the valley bottoms along the main river. 

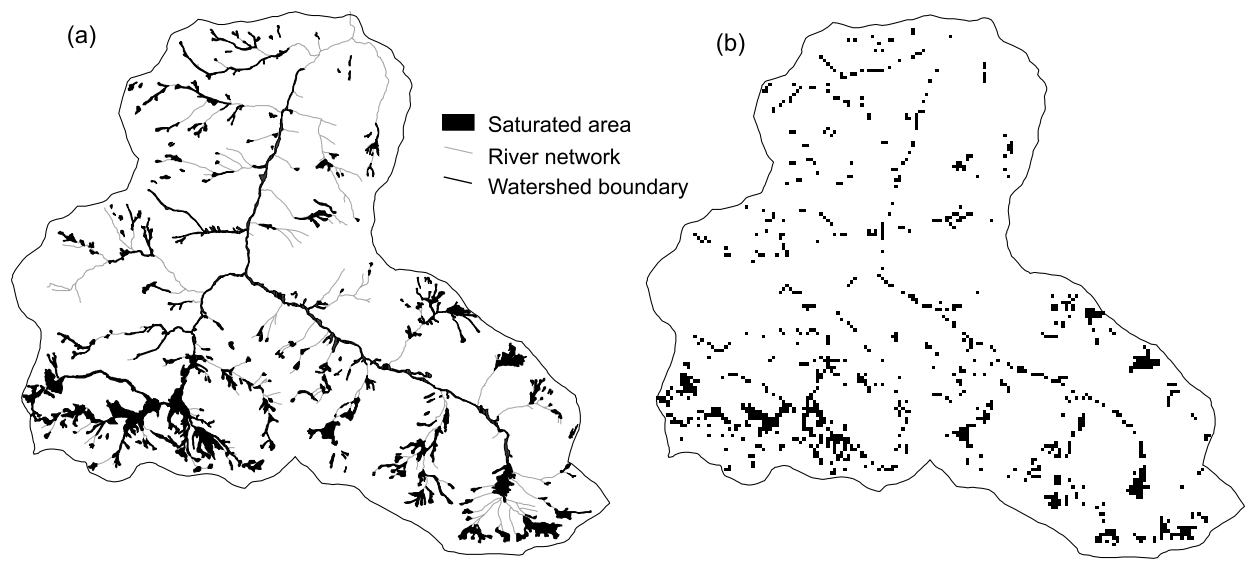

Figure 4. Pattern of mapped saturated areas (b) transformation to the $50 \times 50 \mathrm{~m}^{2}$ grid.

in the Brugga basin: (a) original mapping and (b) transtort

[32] The total size of saturated areas in the Brugga basin is $2.6 \mathrm{~km}^{2}$, which is $6.6 \%$ of the basin area (excluding areas with settlements or other areas that are heavily disturbed by construction) (Figure 4a). Saturated areas occur in narrow strips in the riparian zone along the main rivers (compare Figure 1) and along narrow and steep valleys of tributary creeks, where horizons of springs or diffuse zones of emerging subsurface flow are located at the toe of the hillslopes adjacent to the channel. Saturated areas of larger extent were found in cirques or similar hollow structures of Pleistocene origin and in other hollows with converging morphology. The cirques are often characterized by a roughly bowl-shaped morphology with a low-lying, flat central part where saturated areas occur as bogs.

[33] In line with these field observations, most saturated areas $(66.6 \%$ of the total saturated area) were found in the hollow/channel landscape unit, i.e., in locations with an analytically derived topographic convergence (Figure 5; compare with Figure 2a). Field observations that explain the occurrence of the remaining saturated areas in planes or on ridges are as follows: (1) Saturated areas were found below springs on the steep and locally planar headwalls of the cirques mentioned above. (2) The saturated areas are located close to the watershed divide, only a few meters in altitude below the top of the mountain ridges where they were again related to the occurrence of springs. (3) Saturated areas of larger spatial extent were most often found in the southwestern part of the Brugga basin. In this area, the crystalline bedrock is widely covered by moraine deposits (see Figure 2b) that have denser soils with lower hydraulic conductivity. This leads to a higher potential for surface saturation.

[34] The distribution of saturated areas among the different soil units of the Brugga basin showed that the $20 \%$ fraction of saturated areas is indeed comparatively large for the moraine unit (Figure 6). A similar coverage with saturated areas was found for the Holocene deposits in the valley bottoms, whereas practically no saturated areas were found in units with a boulder layer (Figure 6). The extent of saturated areas in the different elevation zones tends to increase with elevation up to a maximum (about $8 \%$ ) at an elevation of about $900-1100 \mathrm{~m}$. For higher elevations, the fraction of saturated areas remains above the basin average (Figure 7).

[35] After transformation to the $50 \times 50 \mathrm{~m}^{2}$ grid, the pattern of saturated areas appeared more fragmented (Figure 4b). This is also expressed in terms of a smaller patch size and a more regular patch shape for $50 \times 50 \mathrm{~m}^{2}$ as compared to the $10 \times 10 \mathrm{~m}^{2}$ grid (see MPS and MSI in Table 3). For the narrow bands of saturated areas in the valley bottoms, the fraction of area in the larger grid cells was often not sufficient to classify a $50 \times 50 \mathrm{~m}^{2}$ cell as saturated area.

\subsection{Performance of Terrain Indices}

[36] The radiation index (RAD) was found to result in the poorest representation of saturated area spatial patterns

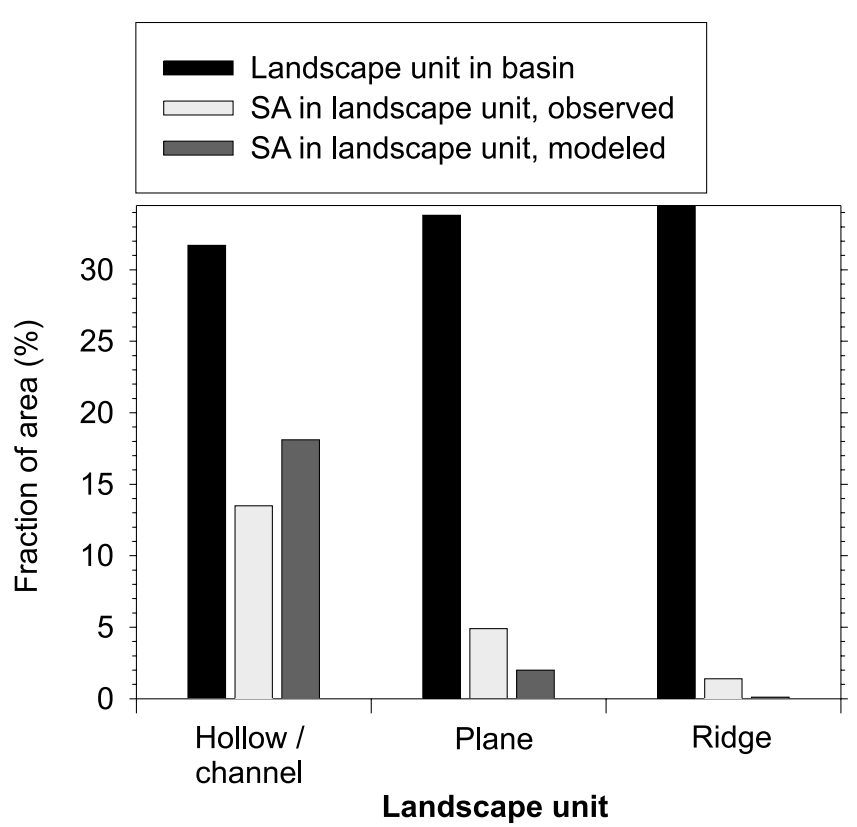

Figure 5. Fraction of area of landscape units on the total area of the Brugga basin and fraction of observed and modeled saturated areas (SA) on the area of the landscape units (model with best $T_{\text {CSWI }}$ terrain index). 


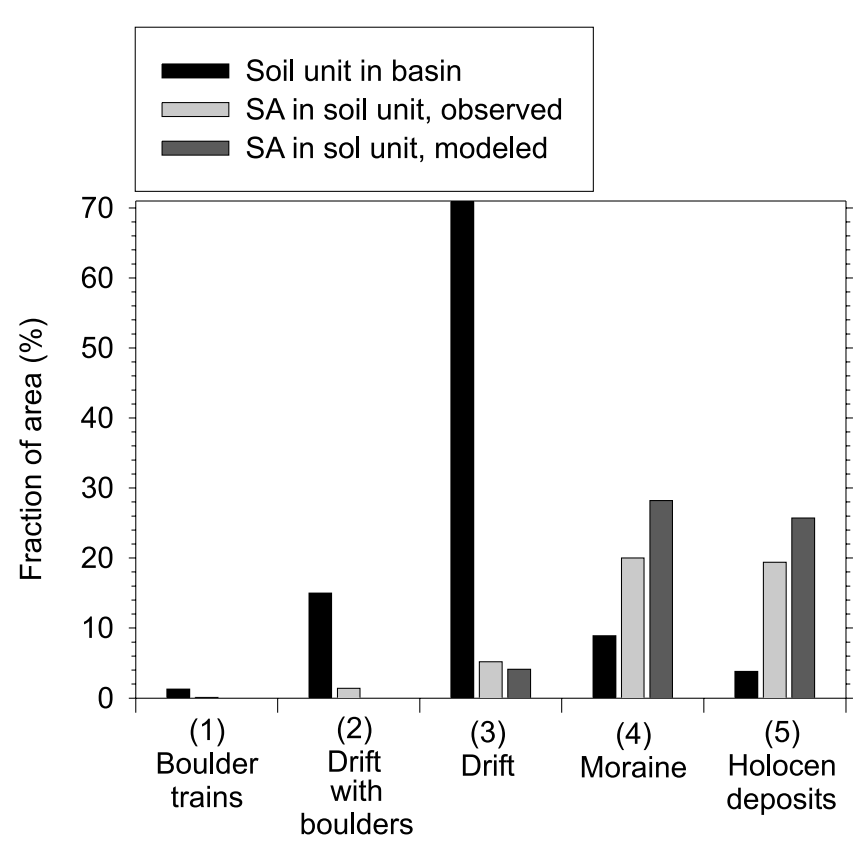

Soil unit

Figure 6. Fraction of soil units on the total area of the Brugga basin and fraction of observed and modeled saturated areas (SA) on the area of the soil units (model with best $T_{C S W I}$ terrain index).

(Figure $8 \mathrm{~b}$ and Table 3). Large patches with the lowest annual radiation input (minimum $529 \mathrm{kWh} \mathrm{m}^{2} \mathrm{a}^{-1}$ ) are mainly located on the lower parts of steep north facing slopes. RAD performed even worse than the random pattern RANDOM. For the pattern of RAD with a clumping of patches in some parts of the study area, the distances between observed and modeled saturated cells $\left(k_{\text {dist }}\right)$ were larger on average than for the random pattern being uniformly distributed in space.

[37] The mean surface curvature (CURV) resulted in a pattern of the most pronounced concavity of the landscape that highlights the bottoms of narrow, deeply incised valleys, mainly in the lower part of the main valley and in its contributing creeks (Figure 8c). These parts frequently correspond to the location of saturated areas. The CURV pattern, however, did not include saturated areas in the valley bottoms of broader, more open valley segments, particularly those in the southwestern part of the basin. Here the most pronounced concavity was found at the rise of the steep hillslopes instead of close to the channel, which is surrounded by comparatively flat terrain. The performance of curvature in quantitative terms was considerably better than was RAD, as it was almost in the range of the performance of the more suitable slope indices (see below and Table 3).

[38] The three different slope indices resulted in markedly different patterns of saturated areas. The worst performance in comparison to the observations was found for $\tan \beta_{3 \times 3}$ (Figure $8 \mathrm{~d}$ and Table 3 ). The pattern of minimum slope values of $\tan \beta_{3 \times 3}$ is dominated by cells close to the watershed divide and in the uppermost parts of the gently undulating highland area in the southwestern Brugga basin. The occurrence of mapped saturated areas in these parts is comparatively low. Only a small number of cells with the lowest slope gradients for the $\tan \beta_{3 \times 3}$ index are attributed to the valley bottoms. This was in contrast to the pattern of the $\tan \beta_{\text {local }}$ index that showed broader patches of saturated areas in the valley bottoms at the expense of areas in more elevated parts of the basin (Figure 8e). The differences are directly due to the calculation methods of both indices. For cells located in the flat valley bottom close to its margins, the adjacent hillslope cells with higher elevation are considered for slope calculation by $\tan \beta_{3 \times 3}$. In the case of $\tan$ $\beta_{\text {local }}$, in contrast, only the adjacent downslope cells in the valley bottom with a comparatively small difference in elevation are considered. Thus tan $\beta_{\text {local }}$ results in smaller slope values than $\tan \beta_{3 \times 3}$. A better performance was achieved for the $\tan \beta_{\text {local }}$ slope method according to all criteria (Table 3 ).

[39] The tendency described as the difference between $\tan \beta_{3 \times 3}$ and $\tan \beta_{\text {local }}$ was amplified when looking at the $\tan \beta_{\mathrm{d}}$ indices. The resulting pattern emphasizes even more the main valley bottoms and adjacent hillslope cells (Figure 8f). The index $\tan \beta_{\mathrm{d}=25}$ performed better than both $\tan \beta_{\mathrm{d}=10}$ and $\tan \beta_{3 \times 3}$ in terms of the $k_{\text {rank }}$ and $k_{\text {match }}$ criteria, but equally well or worse in terms of the fuzzy and the distance criteria (Table 3). The first group of criteria tends to give a higher weight to representing the saturated areas in the main valley bottoms and hollows of the study area, whereas the second group stresses more the ability of the index to represent the spatially scattered distribution of saturated areas.

[40] Using the upslope contributing area as terrain index, the pattern of highest index values was closely related to the channel flow lines in the main valleys and in the major contributing valleys. For the index algorithm using $h=15$ (corresponding to the single flow direction algorithm) the pattern was primarily formed by one single line of cells in

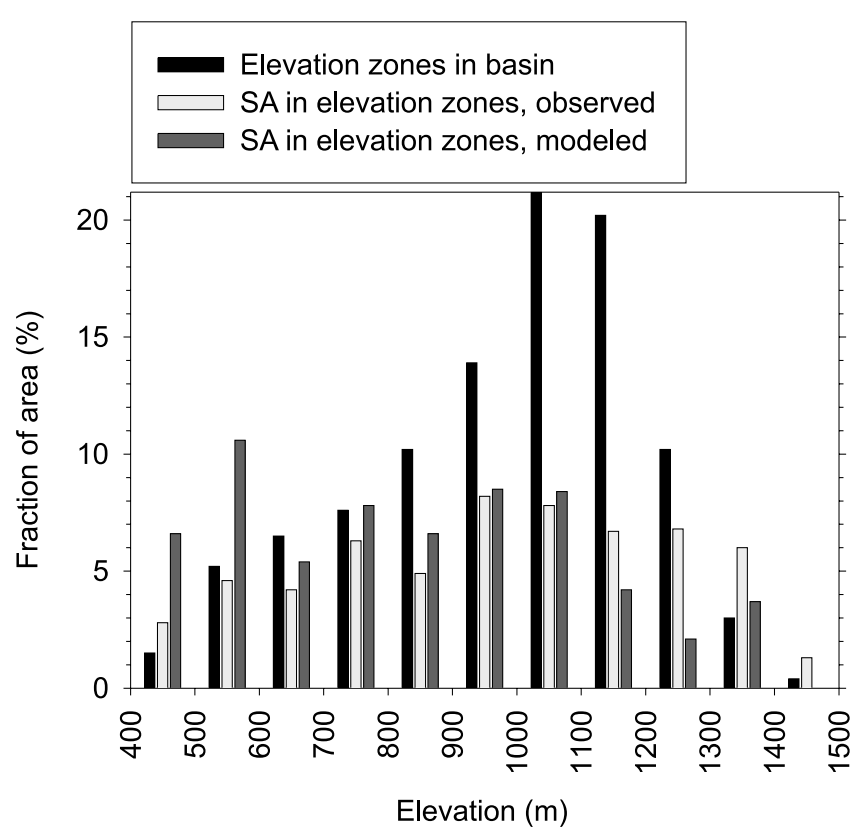

Figure 7. Fraction of elevation zones (100 m contour line intervals) on the total area of the Brugga basin and fraction of observed and modeled saturated areas (SA) on the area of the elevation zones (model with best $T_{C S W I}$ terrain index). 

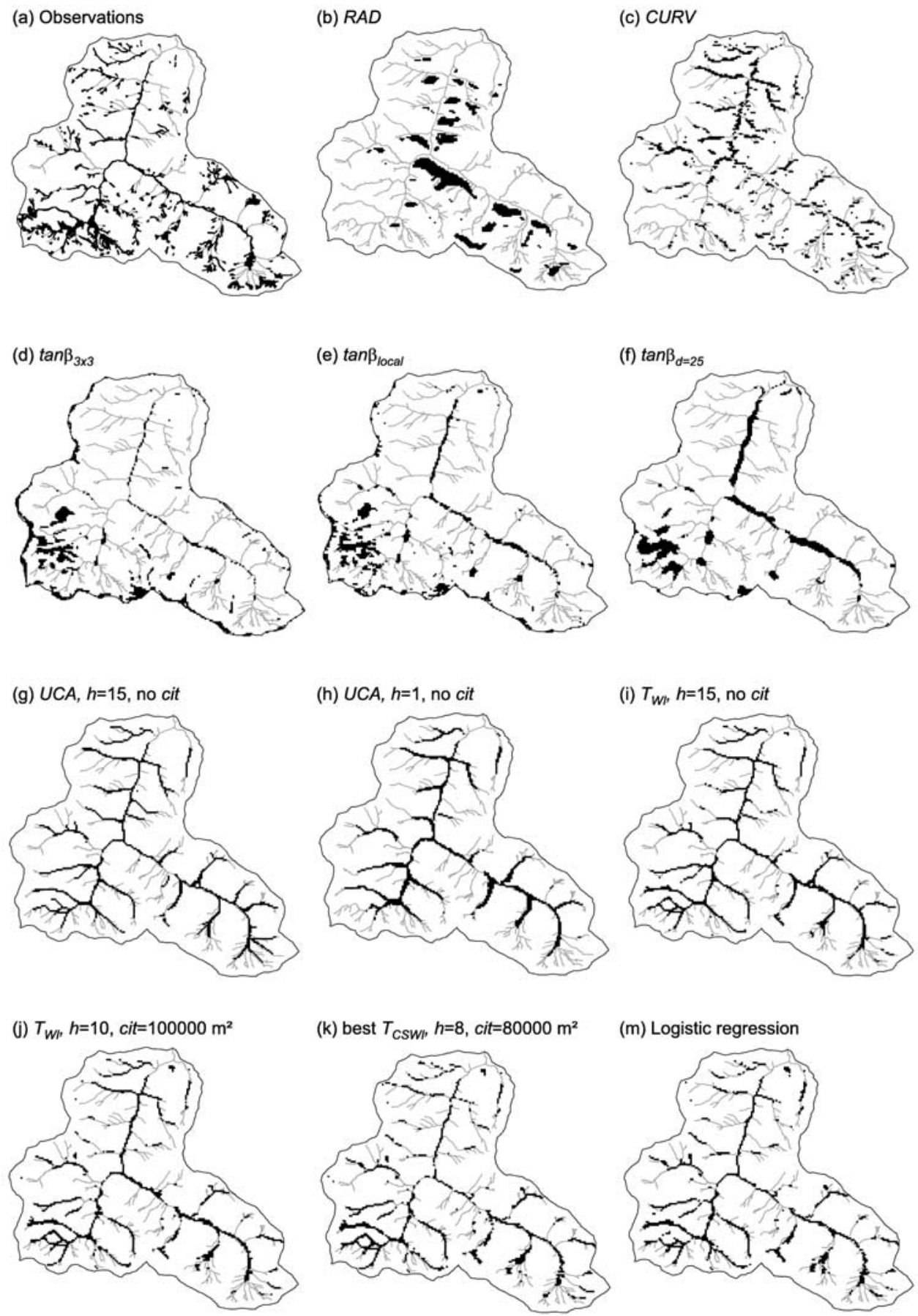

Figure 8. Spatial patterns of (a) observed and (b-m) modeled saturated areas with various terrain indices.

the lowest channel cells of the valleys (Figure 8g). The principal difference in the multiple flow direction algorithm $(h=1)$ (Figure $8 \mathrm{~h})$ was that for the latter, broader areas of saturated cells were generated in the valley bottoms because accumulated area was redistributed among several downslope cells. To compensate, the pattern of saturated cells for $h=15$ extended further into locations of higher elevation in the channel headwaters. For intermediate values of $h$, mixed spatial patterns between these two extreme patterns were obtained. In accordance with the observation that mapped saturated cells are characterized by rather long but narrow strips in the valley bottoms and often located in headwater areas, most performance criteria showed better results for algorithms that calculate the upslope index with stronger flow convergence approaching the single flow direction algorithm (Table 3). Independent from the actual value of $h$, the upslope contributing area index outperformed all the other simple terrain indices. More than $41 \%$ of the observed saturated areas were explained in terms of the fuzzy spatial coincidence $\left(k_{f u z z y}\right)$. 


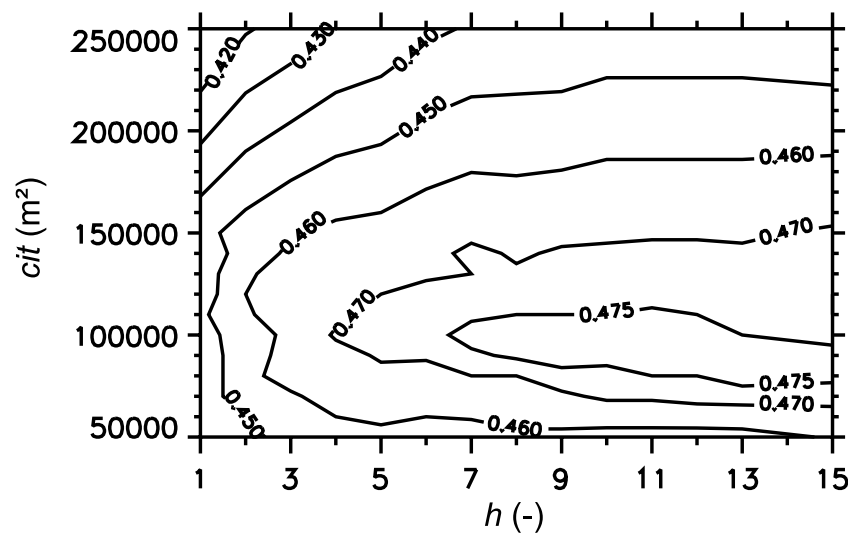

Figure 9. Response surface of the performance criteria $k_{f u z z y}$ for the TOPMODEL wetness index $T_{W I}$ calculated with varying channel initiation threshold CIT and Holmgren factor $h$.

[41] For the example of the single flow direction algorithm $(h=15)$, the combination of slope and contributing area in the form of the TOPMODEL wetness index, $T_{W I}$, performed better than any of the simple indices. Different slope calculation methods used within $T_{W I}$ resulted in only minor differences (Table 3). The main difference between the pattern of saturated cells for any of the $T_{W I}$ indices relative to the UCA index was that in the first case, saturated cells along steep channel segments of tributary creeks were removed (Figure 8i). This was confirmed by the field mapping, where often no saturated areas could be found adjacent to the creeks connecting the hilly upland areas with the valley bottoms over the very steep side slopes of the main valleys. An additional effect in this respect was obtained by introducing the channel initiation threshold (CIT). As the maximum upslope area of each cell is limited by CIT, the slope value gains in relative influence within the combined $T_{W I}$. As a result, more cells along steep channel reaches were removed from the pattern of saturated cells. Instead, additional saturated cells were generated in more elevated areas of the headwaters of tributary valleys, and also partly at the margins of the main valley bottoms (Figure 8j). For simulations of $T_{W I}$ with $\tan \beta$ as slope value and with variations of CIT in the range 0 to $250,000 \mathrm{~m}^{2}$ and for different degrees of flow convergence by varying $h$ in the range 1 to 15 , an optimal pattern of saturated cells according to $k_{f u z z y}$ was obtained for CIT $=100,000 \mathrm{~m}^{2}$ and $h=10$ (Figures 9 and $8 \mathrm{j}$ ). For this parameter combination, the other performance criteria were also close to an optimum value. For CIT values that were too small, too many cells at steeper locations were not included in the pattern of saturated cells. Smaller values of $h$ produced less pronounced converging flow pathways and, as discussed for UCA, patches of saturated areas in the valley bottoms that were too broad.

[42] The modification of $T_{W I}$ with consideration of the climatic water balance $C$ resulted in a small improvement of the spatial pattern of saturated areas $\left(T_{C W I}\right.$ in Table 3$)$, because more saturated cells were predicted in higher rather than in lower parts of the watershed. The differences compared to the index without an elevation gradient were, however, less important than the effect of different algorithms in terms of the parameters $h$ and CIT. Testing a more sophisticated cell-based assessment of the climatic water balance which accounts for the influence of land use and radiation input on evapotranspiration did not further improve the simulated pattern (not shown).

[43] Using the $T_{C W I}$ index with the transmissivity $T$ for the five different soil units given in Table 2 in the form of the climate-soil-topographic index $T_{C S W I}$ resulted in a decrease in performance when compared to the observed saturated pattern (Table 3 ). However, as the $T$ values were only rough estimates, batch simulations were performed to obtain optimum values. $T$ was varied in a range of two orders of magnitude above and below the estimated values for each soil unit. Additionally, $h$ and CIT also varied within the ranges mentioned above. The results showed that one condition for an improved spatial pattern was that no saturated cells occurred in soil units 1 and 2, which was achieved for $\mathrm{T}>1 \times 10^{2} \mathrm{~m}^{3} \mathrm{~d}^{-1}$ in units 1 and 2 . The presence of a very coarse, rapidly draining surface material prevented the formation of surface-saturated areas as corroborated by the field survey (Figure 7). An optimum was reached if both $T_{3}$ and $T_{4}$ were set to $1 \times 10^{1} \mathrm{~m}^{3} \mathrm{~d}^{-1}$ while at the same time setting $T_{5}=4 \times 10^{1} \mathrm{~m}^{3} \mathrm{~d}^{-1}$ (Tables 2 and 3 ). The introduction of the soil information slightly shifted the values of the optimized parameters $h$ and CIT to 8 and $80,000 \mathrm{~m}^{2}$, respectively.

[44] The main difference between $T_{C S W I}$ and $T_{C W I}$ was that for $T_{C S W I}$ the number of saturated cells in the channel part of the valley bottoms with highly permeable sedimentary deposits was reduced. For $T_{C S W I}$, the linear pattern was divided into individual segments in some locations (Figure 8k). These changes came closer to the observed pattern, as quantified by the values of MPS and MSI, where patches in the valley bottoms are highly noncontiguous (Figure 4b). To compensate, and in accordance with the observed pattern, additional saturated cells in $T_{C S W I}$ were generated in zones with moraine or drift material, primarily at the margins of converging zones in valley or hollow structures. If patches of saturated cells already existed for $T_{C W I}$ in the upper parts of the basin, then they were extended for $T_{C S W I}$ toward the watershed divide.

[45] The optimum version of a terrain index found in this study (best $T_{C S W I}$ in Table 3 ) explained $34.2 \%$ of the observed saturated area. Including the coincidence of mapped and modeled areas within a $50 \mathrm{~m}$ tolerance radius with lower weights for distant cells, the explained ratio is $50.7 \%$. The cell-based rank correlation coefficient between index values and the fraction of saturated areas is 0.43 . It is slightly higher (0.49) when averaged over larger areas (i.e., $200 \times 200 \mathrm{~m}^{2}$ cells). For the observed saturated areas, the mean distance to the closest modeled cell is $92 \mathrm{~m}$, which is larger than the distance from each modeled cell to the closest observed saturated area $(66 \mathrm{~m})$. This difference between both $k_{\text {dist }}$ criteria indicates that the observed pattern is more scattered in space than the modeled pattern. Accordingly, the mean size of saturated patches was oversimulated by a factor of about 2.5 , with a more irregular shape than the observed size at the $50 \mathrm{~m}$ grid resolution (MPS and MSI in Table 3).

[46] For the residual patterns, allowing for a tolerance distance of $50 \mathrm{~m}$ due to effects of resolution, grid discreti- 

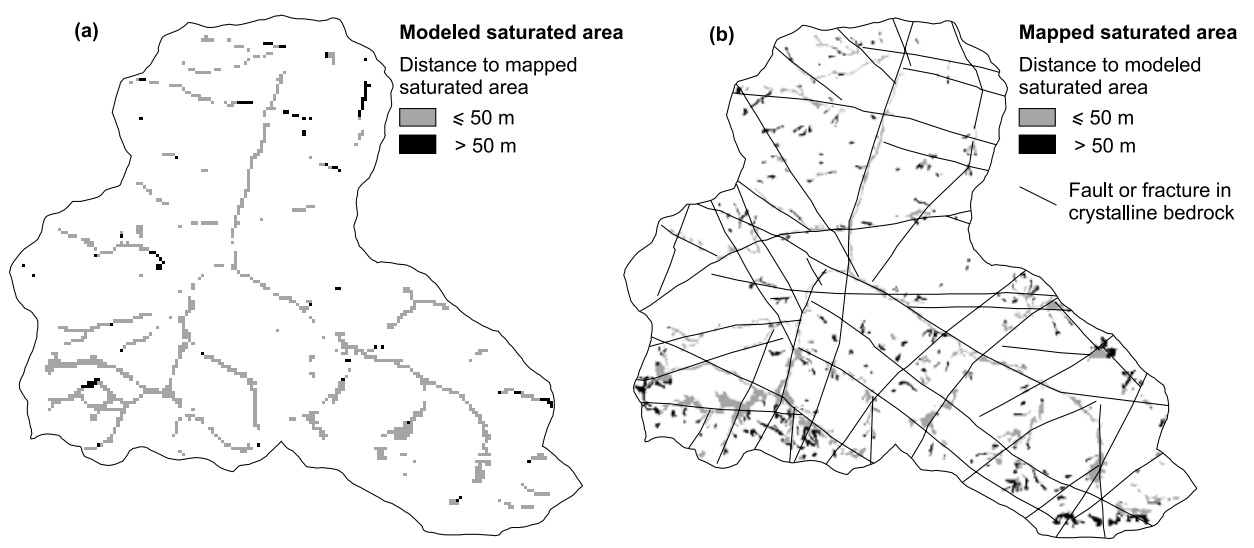

Figure 10. Distance (a) from modeled saturated cells (with best $T_{C S W I}$ terrain index) to next mapped saturated areas and (b) from mapped saturated to next modeled saturated cell. Residual patterns exceeding a tolerance distance of $50 \mathrm{~m}$ are indicated in black. Figure 10b includes the pattern of faults and fractures in the crystalline bedrock.

zation, and uncertainties of location, only $9 \%$ of all modeled saturated cells with $T_{C S W I}$ were at a larger distance relative to any observed saturated area (Figure 10a). These residuals tend to be located close to urban or disturbed areas particularly in the northern part of the basin (compare with Figure 1). Thus one explanation for the deviations is human impact, e.g., by drainage of wet zones. From the point of view of the observed pattern, 33\% of mapped saturated areas were at a distance of more than $50 \mathrm{~m}$ to the next modeled saturated cell (Figure 10b). The pattern of residuals is composed of small patches scattered throughout the entire study area. In general, they tend to occur in elevated parts of the basin, which is also shown by the underestimation of the fraction of saturated areas on different elevation zones (Figure 7). A large number of errors were found in zones located within a short distance downslope of the watershed divide, especially in the southern and eastern parts of the basin. These residual patches are often close to the location of faults and fractures in the crystalline bedrock (Figure 10b). The simulated pattern overestimated the fraction of saturated areas in the hollow/channel landscape unit at the expense of those in plane or ridge positions (Figure 5). For the soil units, the fraction of saturated areas was overestimated in moraine material and Holocene deposits, while the saturated area fraction in the periglacial drift material, which has a large spatial extent in the study area, was underestimated (Figure 6).
[47] The results of the logistic regression indicated that, on average, the probability for a cell to belong to the saturated areas almost doubled when $T_{W I}$ increased by 1 (Table 4). Cells close to tectonic faults were twice as likely to belong to the saturated areas as those more distant from faults. Saturated areas were more than twice as likely in areas with poorly conductive soils as they were in those with higher conductivities. Location in a topographic depression increased the probability by about $60 \%$. The predicted pattern of saturated areas, given by the cells with highest probability of saturation, was similar to the pattern of the best $T_{C S W I}$ version (Figure $8 \mathrm{~m}$ ). The quantitative performance criteria were in general slightly worse than the values of the best $T_{\text {CSWI }}$, but about equal to the other combined terrain indices (Table 3). One notable exception is $k_{\text {rank,200, which had its optimum value among all analyzed }}$ indices for the pattern derived from the logistic regression. This indicates that at the coarser scale of $200 \times 200 \mathrm{~m}^{2}$, areas of high probability of soil saturation tended to coincide more frequently with a high fraction of observed saturated areas than for the other index patterns. Presumably, the reason for this is that logistic regression accounts for additional information on terrain characteristics that favor soil saturation in the neighborhood of each grid cell (as done by the channel/hollow landscape unit classification and by the location close to a bedrock fault or fracture). This larger radius of consideration of terrain characteristics

Table 4. Results of Logistic Regression ${ }^{\mathrm{a}}$

\begin{tabular}{lccccc}
\hline Independent Variable & Constant $b_{0}$ & $T_{W I}$ & Tectonics $^{\mathrm{b}}$ & Landscape Unit $^{\mathrm{c}}$ & Soil $^{\mathrm{d}}$ \\
\hline${\text { Parameter estimate } b_{i}}^{\mathrm{c}}$ & -8.67 & 0.63 & 0.76 & 0.49 & 0.85 \\
Odds ratio $^{\mathrm{e}}$ & & 1.87 & 2.13 & 1.63 & 2.34 \\
& & $(1.78-1.97)$ & $(1.79-2.53)$ & $(1.39-1.93)$ & $(1.90-2.88)$ \\
\hline
\end{tabular}

\footnotetext{
${ }^{\mathrm{a}}$ Dependent variable $y(y=0$ : nonsaturated, $\mathrm{n}=14460 ; y=1$ : saturated, $\mathrm{n}=1012)$.

${ }^{\mathrm{b}}$ Value is 1 for cells closer than $100 \mathrm{~m}$ to fault or fractures, value is 0 otherwise.

${ }^{\mathrm{c}}$ Value is 1 for cells in hollow/channel unit, value is 0 otherwise.

${ }^{\mathrm{d}}$ Value is 1 for soils with low transmissivity (units 3 and 4 in Table 2), value is 0 for more conductive soils (units 1, 2, and 5 in Table 2).

${ }^{\mathrm{e}}$ For unit change; $95 \%$ confidence interval is in parentheses.
} 


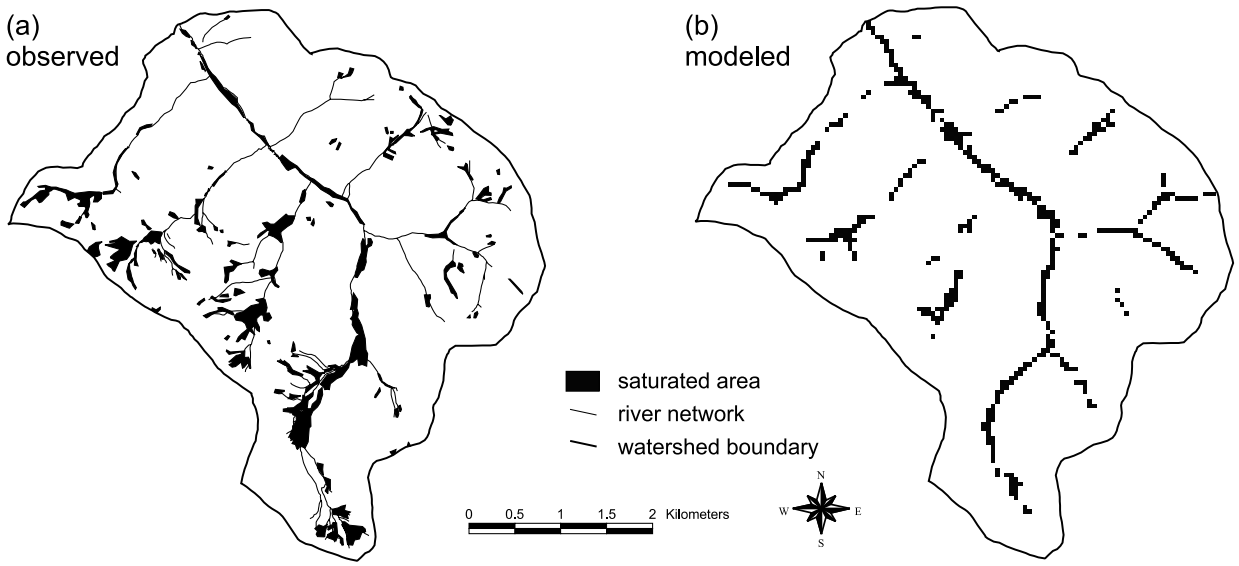

Figure 11. (a) Observed and (b) modeled saturated areas in the Zastler basin (using the best index version, $T_{C S W I}$, as derived in the Brugga basin).

improved the prediction of zones with high coverage of saturated areas at the corresponding larger spatial scale, as analyzed by $k_{\text {rank,200 }}$.

\subsection{Evaluation for the Zastler Basin}

[48] Field mapping in the neighboring Zastler basin $\left(18.4 \mathrm{~km}^{2}\right)$ resulted in a saturated area fraction of $6.2 \%$ of the basin total. This is close to the fractional area observed in the Brugga basin (6.6\%). The main features of the spatial pattern, such as patch size and shape, were also similar to those of the Brugga basin (Figure 11a and MPS and MSI in Table 5). The various terrain indices tested in the Brugga basin were also applied in the Zastler basin to assess the transferability of the approach to another area with similar physiographic characteristics.

[49] The upslope contributing area index (UCA), was the best primary index to explain the observed saturated patterns in the Zastler basin (Table 5). Similar to the Brugga basin, the basic single-flow and multiple-flow algorithms for the calculation of $T_{W I}$ performed less successfully than a modified $T_{W I}$ with adjusted parameters $h$ and CIT. For the best parameter combination derived for $T_{W I}$ in the Brugga basin $\left(h=10\right.$, CIT $\left.=100,000 \mathrm{~m}^{2}\right)$, the resulting pattern in the Zastler basin matched the observations with similar performance. Repeating the optimization for the Zastler by varying $h$ and CIT led to a lower value of CIT $=60,000 \mathrm{~m}^{2}$ while $h$ was also found to be 10 at the optimum. This optimized version produced some saturated cells both in hollows of higher elevation and in the valley bottoms that were closer to the observations. The performance of the optimized index was slightly better than in the Brugga basin. The best combined index including climate and soil influence which was found for the Brugga basin (best $T_{\text {CISWI }}$ ) resulted in a nearly identical performance in the Zastler (Table 5 and Figure 11b). The general pattern of errors when comparing the observations and simulations was similar to that described for the Brugga basin. In general, the performance of terrain indices in the validation basin did not differ significantly from that in the Brugga basin, neither what concerns absolute values of performance, nor in terms of the ranking of terrain index suitability.

\section{Discussion}

\subsection{Interpretation and Suitability of the Performance Criteria}

[50] The set of performance criteria used in this study was found to provide valuable quantitative measures for evaluating the performance of modeled relative to observed

Table 5. Performance of Terrain Indices to Represent the Observed Pattern of Saturated Areas in the Zastler Basin

\begin{tabular}{|c|c|c|c|c|c|c|c|c|c|c|c|c|}
\hline & \multirow[b]{2}{*}{ CIT, ha } & \multirow[b]{2}{*}{$h$} & \multicolumn{10}{|c|}{ Criteria } \\
\hline & & & MPS, ha & MSI & $k_{\text {rank,50 }}$ & $k_{\text {rank,200 }}$ & $\begin{array}{c}k_{\text {match,10 }} \\
\%\end{array}$ & $\begin{array}{c}k_{\text {match,50 }} \\
\%\end{array}$ & $\begin{array}{c}k_{f u z z y}, \\
\%\end{array}$ & $\begin{array}{c}k_{\text {dist }, o} \\
\mathrm{~m}\end{array}$ & $\begin{array}{c}k_{\text {dist }, m} \\
\mathrm{~m}\end{array}$ & $\begin{array}{c}k_{\text {dist,mean }}, \\
\mathrm{m}\end{array}$ \\
\hline Perfect fit value & - & - & - & - & -1 or 1 & -1 or 1 & 100 & 100 & 100 & 0 & 0 & 0 \\
\hline Worst case value & - & - & - & - & 0 & 0 & 0 & 0 & 0 & $\infty$ & $\infty$ & $\infty$ \\
\hline \multicolumn{13}{|l|}{ Observed patterns } \\
\hline O10 (10 m grid) & - & - & 1.15 & 3.02 & - & - & - & - & - & - & - & - \\
\hline O50 (50 m grid) & - & - & 1.36 & 2.12 & - & - & - & - & - & - & - & - \\
\hline \multicolumn{13}{|l|}{ Simple indices } \\
\hline UCA & - & 1 & 9.06 & 6.95 & 0.356 & 0.405 & 27.5 & 28.0 & 38.3 & 212 & 105 & 159 \\
\hline \multicolumn{13}{|l|}{ Combined indices } \\
\hline$T_{W I}$ with $\tan \beta_{\text {local }}$ & - & 1 & 7.77 & 9.08 & 0.420 & 0.499 & 32.9 & 34.0 & 45.7 & 137 & 86 & 112 \\
\hline$T_{W I}$ with $\tan \beta_{\text {local }}$ & - & 15 & 9.06 & 10.73 & 0.416 & 0.503 & 29.5 & 31.5 & 43.4 & 138 & 81 & 110 \\
\hline$T_{W I}$ with $\tan \beta_{\text {local }}$ & 10 & 10 & 3.63 & 3.50 & 0.423 & 0.511 & 35.0 & 37.0 & 50.2 & 96 & 77 & 87 \\
\hline$T_{W I}$ with $\tan \beta_{\text {local }}$ & 6 & 10 & 2.86 & 2.80 & 0.426 & 0.514 & 37.0 & 39.3 & 52.2 & 97 & 69 & 83 \\
\hline best $T_{C S W I}$ (Brugga) & 8 & 8 & 3.20 & 3.51 & 0.429 & 0.517 & 35.5 & 37.9 & 50.6 & 99 & 74 & 87 \\
\hline
\end{tabular}


Table 6. Spearman's Rank Correlation Coefficient Between the Performance Criteria of the 19 Terrain Indices Compared in Table 3

\begin{tabular}{lccccccccc}
\hline & $k_{\text {rank }, 50}$ & $k_{\text {rank }, 200}$ & $k_{\text {match }, 10}$ & $k_{\text {match }, 50}$ & $k_{\text {fuzzy }}$ & $k_{\text {dist }, o}$ & $k_{\text {dist }, m}$ & $k_{\text {dist }, \text { mean }}$ \\
\hline$k_{\text {rank }, 50} 1.00$ & 0.98 & 0.87 & 0.84 & 0.78 & -0.77 & -0.80 & -0.81 \\
$k_{\text {rank }, 200}$ & & 1.00 & 0.83 & 0.80 & 0.80 & -0.79 & -0.75 & -0.82 \\
$k_{\text {match }, 10}$ & & & 1.00 & 0.99 & 0.94 & -0.86 & -0.95 & -0.90 \\
$k_{\text {match }, 50}$ & & & & 1.00 & 0.93 & -0.86 & -0.94 & -0.90 \\
$k_{\text {fuzzy }}$ & & & & & 1.00 & -0.94 & -0.86 & -0.97 \\
$k_{\text {dist }, o}$ & & & & & & 1.00 & 0.80 & 0.99 \\
$k_{\text {dist }, m}$ & & & & & & & & 1.00 & 0.84 \\
$k_{\text {dist, }, \text { mean }}$ & & & & & & & & 1.00 \\
\hline
\end{tabular}

spatial patterns. The criteria gave objective advice on the ranking of different indices according to their predictive power, which corresponded to the qualitative reasoning obtained by visual inspection. Strong correlations between several individual criteria were found (Table 6). $k_{\text {match,10 }}$ and $k_{\text {match,50, }}$, as well as $k_{\text {rank,50 }}$ and $k_{\text {rank,200, resulted in a }}$ nearly identical ranking of index performance. This indicates that the spatial resolution of the validation data set (saturated patterns on a 10, 50, or $200 \mathrm{~m}$ grid), although appearing to differ with regard to the complexity of shape of saturated patches (Figures $4 \mathrm{a}$ and $4 \mathrm{~b}$ and MSI in Table 3), had no influence on the selection of an optimum terrain index. An exception was found for the pattern derived from logistic regression, which was rated as the best pattern in

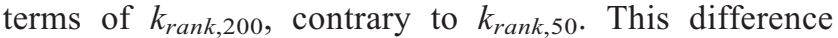
between both criteria indicates that, depending on the scale of evaluation, individual terrain characteristics may have a different value for explaining the location of saturated areas (see section 4). Using the same type of performance criteria but at different spatial resolutions (such as the pairs $k_{\text {match, } 10}$ and $k_{\text {match,50 }}$ or $k_{\text {rank,50 }}$ and $k_{\text {rank,200 }}$ ) can thus give valuable information on scaling issues.

[51] A high correlation coefficient was also found between $k_{\text {match, } 10}$ or $k_{\text {match,50 }}$ and $k_{\text {fuzzy }}$ (Table 6). Nevertheless, some important differences in the ranking of terrain indices existed between these criteria. Consider, for instance, the slope indices $\tan \beta_{\text {local }}$ and $\tan \beta_{d=25}$. According to $k_{\text {match }}$, $\tan \beta_{d=25}$ performs better than tan $\beta_{\text {local }}$, contrary to what might be expected from visual inspection. In the case of tan $\beta_{d=25}$, broad patches of saturated areas in valley bottoms captured the mostly narrow mapped saturated areas in these parts. In contrary, the probability of missing the exact location of these mapped areas due to uncertainties of data and due to resolution effects was higher for the finer pattern of $\tan \beta_{\text {local }}$. In terms of criterion $k_{f u z z y}$, these accidental discrepancies between observed and modeled patterns are taken into account by the fuzzy approach whereas $k_{\text {match }}$ only considers the direct coincidence. Thus $\tan \beta_{\text {local }}$ performed slightly better in terms of $k_{f u z z y}$ than $\tan \beta_{\mathrm{d}=25}$. Similarly, $k_{\text {match }}, k_{\text {rank,50, }}$ and $k_{\text {rank,200 }}$ tended to have a higher performance for the more clumped than for the finer patterns (see $T_{W I}$ with $h=1$ versus $T_{W I}$ with $h=15$ as a further example). In other words, instead of using $k_{\text {rank }}$ or $k_{\text {match }}$, the simulated pattern is better evaluated by $k_{f u z z y}$ because of the widely scattered and fine shape of the observed pattern.

[52] A similar reasoning applies to the distance criteria, where for $k_{\text {dist,o }}$, contrary to $k_{\text {dist, } m}$, high performance values can only be obtained for those indices that also have a scattered pattern with a number of saturated cells away from the main valleys. The three distance criteria $k_{\text {dist }}$ provide a method to quantify in an illustrative way the location of observed and modeled patterns relative to each other. The combined criterion $k_{\text {dist,mean }}$ is useful for evaluating both aspects of pattern coincidence, i.e., from the perspective of both observed and simulated patterns. However, one needs to be cautious when interpreting the index performance. It is important to note that the best results of all simple terrain indices in terms of $k_{\text {dist,o }}$ were obtained for the random index (Table 3), which has a spatial pattern that provides a comparatively near-distance modeled cell for each observed saturated cell. One might risk misinterpreting the increase in quantitative performance according to these criteria as a real increase of the physically based predictive power of a certain index to explain the observed patterns. The main problem with the distance criteria is that an index (e.g., as the random index) may produce saturated cells that are closer to the observations than for another index, but that are still too far away to give a physically meaningful interpretation of the observations. A better criterion in this respect is the fuzzy coincidence criteria $k_{f u z z y}$, which sets a maximum distance up to which a reasonable relation between observations and model results can still be assumed considering the existing uncertainties.

\subsection{Factors Influencing the Location of Saturated Areas and Their Incorporation in Terrain Indices}

[53] The upslope contributing area was found to be the most important single factor explaining the spatial pattern of saturated areas in the Brugga basin. This result corresponds to findings of Western et al. [1999] for the explanation of soil moisture patterns under wet conditions in the Tarrawarra catchment. The importance of the upslope contributing area is an indication that soil saturation does mainly depend on the amount of lateral flow toward a certain location. The upslope area was found to be superior to topographic indices that considered the local and/or downslope process control on lateral water transport, i.e., slope gradient (slope indices) and flow convergence (curvature index). Because of high precipitation volumes and comparatively low evaporation, the Brugga basin usually is in a wet state throughout the year, which favors the dominance of nonlocal control. This process dominance is reflected in the observed pattern of saturated areas and, consequently, by the better performance of terrain indices representing nonlocal control. Combining local and nonlocal topographic aspects by the TOPMODEL wetness index resulted in a distinct, but quantitatively small, improvement of the predicted pattern. The shape of this pattern, however, was dominated by the UCA index pattern, which is a consequence of the relative weight attributed to each component in the combined index. For the topographic wetness index, this weighting is based on a theoretical derivation using a number of assumptions [Beven and Kirkby, 1979], but of course an alternative combination might perform better. However, using UCA and slope as separate variables in the logistic regression did not give a clue for such an alternative weighting. 
[54] The performance of the various topography-based terrain indices was sensitive to the algorithms and their parameterization used for deriving slope and flow accumulation from the gridded elevation model: (1) The generally better performance of $\tan \beta_{\text {local }}$ in comparison to $\tan \beta_{3 \times 3}$ is physically plausible as local moisture conditions are largely controlled by drainage and thus downslope topography. Using the surface slope to the adjacent downslope cell (tan $\beta_{\text {local }}$ ) outperformed the downslope index, $\tan \beta_{\mathrm{d}}$. The primary reason might be that in this catchment saturated areas often occur in locally flat patches within a generally steep topography rather than in extended plane valley bottoms with a continuous groundwater body. (2) Using values of 8-10 for the Holmgren factor $h$ in the upslope area calculations provided the most realistic patterns of saturated areas. This is in line with recommendations from other studies to use an intermediate approach between the single- and multipleflow-direction algorithms to adequately represent the real flow redistribution in view of the limitations induced by the regular grid data [e.g., Holmgren, 1994; Tarboton, 1997]. In contrast to Holmgren [1994], who recommended $h$ values of 4-6 based on a theoretical analysis for a $50 \times$ $50 \mathrm{~m}^{2}$ DEM, our optimized values are slightly higher, resulting in stronger converging flow patterns, which can be attributed to the frequently linear shape of observed saturated areas. (3) The introduction of the channel initiation threshold (CIT) resulted in considerable improvement of the saturated area pattern. This is physically reasonable, as subsurface flow that enters the channel network usually does not influence soil moisture status at downslope locations. The use of some threshold area is especially important in large-scale applications. The continuous accumulation of upslope contributing area toward the basin outlet would imply that zones along the main river are increasingly more prone to saturation. In the Brugga basin, and other catchments, this is often not the case. The appropriate value of the threshold area CIT might vary depending on catchment characteristics such as geology or climate. Quinn et al. [1995] suggested a value of $22,500 \mathrm{~m}^{2}$ based on an analysis of the distribution functions of $T_{W I}$ for different CIT values. Values for CIT of $60,000-100,000 \mathrm{~m}^{2}$ provided the best agreement with observed patterns of saturated areas in our study. These values also happened to provide a channel network that agreed reasonably well with the official topographic map (scale 1:50,000).

[55] Only small improvements for the prediction of saturated areas were achieved by including nontopographic factors. A slight improvement was obtained by using an elevation gradient for the water balance $\left(T_{C W I}\right)$. This, however, did not substantially remove the underestimation of saturated areas in elevated parts of the catchment (Figure 7). One may argue that important climatic aspects influencing water balance variability are not captured (e.g., precipitation patterns influenced by topography, snow redistribution by wind drift). Additionally, the simple radiation index (RAD) shows that zones of minimum radiation input, which could be assumed to be wettest, often coincide with steep slopes with comparatively permeable soils that preclude the formation of saturated areas (Figures $8 \mathrm{~b}$ and $2 \mathrm{~b}$ ). The generally wet conditions caused by the positive water balance of the Brugga basin might be another reason why the local control by evaporation might be less important for the soil moisture status. This clearly differs from the results of Western et al. [1999] or Gómez-Plaza et al. [2001], where for dry environments, or those with a clear dry season, a better performance of terrain indices that accounted for insolation was shown.

[56] The logistic regression indicated that the occurrence of saturated areas tended to be related to soils of low transmissivity. However, an improvement of the simulated pattern by a combined soil-topographic index was achieved only after an optimization of the transmissivity values. This situation will be typical for most basin-scale applications, where the available soil information in terms of the detail of differentiation into different soil types, spatial resolution and parameter values is limited and usually less accurate than other data, especially topographic data. In this case, a priori soil information fails to improve the prediction of saturated areas. A limited value of using physical soil properties based on the spatial distribution of soil types to improve the simulation of patterns of surface soil moisture or surface runoff generation was also reported by Vertessy and Elsenbeer [1999], Houser et al. [2001], and Western and Grayson [2001].

[57] The intersection of fractures and faults in the crystalline bedrock with the terrain surface can lead to the emergence of deep groundwater from the fissured aquifer in springs [Uhlenbrook et al., 2002] and thus saturated areas. Many of the small patches of residuals throughout the study area (Figure 10b) were indeed found in the field to be caused by springs. Additionally, denser patches of residuals that occurred in zones a short distance downslope of the watershed divide (Figure 10b) may be related to springs at the boundary between the unconsolidated material and the underlying bedrock that emerges at the transition from the hilly uplands to the steep slopes of the main valleys. Ambroise et al. [1996] and Freer et al. [1997] recognized similar influence of preferential subsurface flow paths or of bedrock topography on saturated area formation. As these springs are not necessarily related to a distinct convergence of the terrain surface, this may also partly explain the location of saturated areas in landscape units classified as plane or ridge that were underestimated by the terrain indices used here (Figure 5).

[58] There is no direct way to compare the index performance with previous findings due to the lack of studies that similarly evaluated a binary spatial pattern against observations for large areas. Assessing the performance of mainly topography-based terrain indices for explaining observed soil moisture patterns in small basins, the explained variance in a number of studies in different environments was usually less than $50 \%$ (see overview by Western et al. [1999]). The best value was obtained by Western et al. [1999], where a combined index of the TOPMODEL wetness index and potential solar radiation explained up to $61 \%$ of the spatial variation of soil moisture during wet periods in a 10.5 ha test site. The results of our study, with the best terrain index explaining about $50 \%$ of the observed pattern of saturated areas in terms of the fuzzy performance criteria, is in the range of previous studies. A number of factors cause the large percentage of unexplained locations 
of saturated areas and limit the predictive capability of terrain indices.

[59] 1. Terrain indices do not incorporate all processes that control soil saturation. The most relevant factor for the study area that was not included in a terrain index as we did not find a manageable way to do so, was geology, especially fractures and stratum boundaries.

[60] 2. An appropriate way to incorporate influencing factors into a terrain index is often not known a priori. This refers both to index algorithms and their parameter values (as the relevance of CIT and $h$ for upslope contributing area calculations in our study), and to the relative weights attributed to the individual factors within a combined index. These features can be derived only by regression analysis or optimization against observed patterns. Much broader experience from a large number of studies would be required to devise rules concerning how to incorporate influencing factors a priori for given basin characteristics.

[61] 3. The available information on influencing factors beyond topography is not detailed enough to explain additional organization of the saturated pattern. This will be the case particularly for large-scale applications. The lack of detailed information on soil relative to topography is considered to be a major limitation on the accuracy of simulated patterns at the basin scale. In contrast, land use, another factor that may cause additional variability in saturated patterns in particular at large scales, is usually available in more detail, e.g., from remote sensing. In other areas, correlations between land use and soil patterns may help to expand the spatial soil information used in index calculations.

[62] 4. Scale discrepancies between the resolution of the modeling scale and the observation scale limit the maximum accuracy that can be expected of an index model. This includes subgrid features that cannot be resolved by the model resolution, as well as geometric discrepancies resulting from data discretization, e.g., to a regular grid. Smallscale features, however, such as microtopography at the $10 \mathrm{~m}$ scale, are governing processes that are not relevant to the prediction of saturated areas at the basin scale. Thus with adequate measures such as the fuzzy criterion, this scale effect can be minimized when evaluating simulated versus observed patterns at the basin scale.

[63] 5. Uncertainty in the delineation of observed patterns as well as in the exact position of data underlying the modeled patterns can contribute to high unexplained spatial variability of saturated areas. In contrast to most other studies, the delineation of observed spatial patterns used here was based on long-term mean wetness conditions. Thus uncertainty of location due to the temporal variability of the mapped pattern relative to the simulated pattern of a static index is excluded. On the other hand, the methodology includes uncertainty of pattern delineation due to the qualitative character of pedological and geobotanical mapping indicators. Additionally, errors of digital elevation models may limit model performance in hydrogeomorphological applications particularly at smaller scales [e.g., Endreny et al., 2000]. We assume $50 \mathrm{~m}$ as a reasonable tolerance distance for these uncertainties of location for our application.

[64] 6. Natural variability of landscape characteristics adds a random component to the spatial pattern of saturated areas that cannot be predicted using deterministic indices and thus limits their predictive power.

\section{Conclusions}

[65] In this study, the use of qualitative botanical and pedological observations was valuable to achieving a consistent, time-integrated delineation of water saturated areas throughout a mesoscale river basin. The resulting spatial pattern allowed evaluation of the power of static terrain indices to predict the spatial distribution of saturated areas at the basin scale. Upslope contributing area was the most important single factor to explain the observed pattern. The combination with slope in the form of the well-known topographic wetness index $\ln (a / \tan \beta)$ improved the simulated spatial pattern of saturated areas. We tested various modifications of the wetness index to further improve the results. While these partially resulted in a somewhat better prediction of saturated areas, there seemed to be a limit to what can be achieved with this type of approach.

[66] For computation of the upslope contributing area we found that the selection of an appropriate algorithm for calculating flow accumulation from the grid-based elevation model is essential for improving the performance of the simulated pattern. We recommend use of an intermediate approach between a single- and multiple-flow-direction algorithm and a threshold value to limit large accumulation of contributing area along the stream network. The latter is especially important when the wetness index approach is transferred to a large scale.

[67] Factors other than topography were of less value to the improvement of the explanatory power of combined terrain indices. We argue that a main reason might be limited data availability. In particular, the performance of a combined soil-topography index is limited by the rather approximate kind of soil information available at large scales. A general limitation of the type of deterministic index approach is the difficulty of quantitatively including categorical attributes such as geological features like fractures or strata boundaries. The results in our study area indicated, however, that such features partly explain the spatial pattern of saturated areas.

[68] There is no standard criterion for evaluating a simulated spatial pattern in comparison to an observed pattern such as the model efficiency for evaluating runoff simulations. We proposed a number of evaluation criteria. Obviously there is much redundancy in these criteria, but they nevertheless provide different information about the agreement of simulated and observed patterns. On the basis of our results, we recommend using not only criteria that are based on a cell-by-cell comparison but also measures that examine the cell neighborhood.

[69] On the basis of the validation in an independent catchment, we conclude that the best version of a combined terrain index including topography, soil, and climate attributes is a reasonable approach to represent characteristic features of the observed pattern of saturated areas in the study area. Although missing smaller-scale detail and some influencing factors, it is considered to be transferable to other mountainous basins on crystalline bedrock in the Black Forest region. The transferability to basins with markedly different physiographic characteristics remains 
to be tested, in particular for less humid areas where land use and evapotranspiration might play a more important role. However, we suggest that the combination of topographic indices with other easily available spatial information provides a simple approach to estimate the general patterns of saturated areas.

[70] Acknowledgments. The authors thank for the financial support received from the German research foundation (Deutsche Forschungsgemeinschaft, DFG, Bonn, Germany, grant Le 698/12-1) and from the Swedish Research Council (grant 620-20001065/2001).

\section{References}

Ambroise, B., K. Beven, and J. Freer (1996), Application of a generalized TOPMODEL to the small Ringelbach catchment, Vosges, France, Water Resour. Res., 32(7), 2147-2159.

Anderson, M. G., and T. P. Burt (1990), Process Studies in Hillslope Hydrology, John Wiley, Hoboken, N. J.

Barling, R. D., I. D. Moore, and R. B. Grayson (1994), A quasi-dynamic wetness index for characterizing the spatial distribution of zones of surface saturation and soil water content, Water Resour. Res., 30(4), 10291044.

Beven, K. J. (1986), Hillslope runoff processes and flood frequency characteristics, in Hillslope Processes, edited by A. D. Abrahams, pp. $187-$ 202, Allen and Unwin, Concord, Mass.

Beven, K. J., and M. J. Kirkby (1979), A physically based, variable contributing area model of basin hydrology, Hydrol. Sci. Bull., 24(1), 4370 .

Beven, K. J., and M. J. Kirkby (1993), Channel Network Hydrology, John Wiley, Hoboken, N. J.

Blazkova, S., K. J. Beven, and A. Kulasova (2002), On constraining TOPMODEL hydrograph simulations using partial saturated area information, Hydrol. Processes, 16, 441-458.

Burrough, P. A. (1986), Principles of Geographical Information Systems for Land Resources Assessment, Monogr. Soil Resour. Surv., vol. 12 Clarendon, Oxford, U. K.

Burt, T. P., and D. P. Butcher (1985), Topographic control of soil moisture distributions, J. Soil Sci., 36, 469-486.

Cohen, J. (1960), A coefficient of agreement for nominal scales, Educ. Psychol. Meas., 20(1), 37-46.

Constanza, R. (1989), Model goodness of fit: A multiple resolution procedure, Ecol. Modell., 47, 199-215.

Costa-Cabral, M., and J. Burges (1994), Digital elevation model networks (DEMON): A model of flow over hillslopes for computation of contributing areas and dispersal areas, Water Resour. Res., 30(6), 1681-1692.

Curmi, P., P. Durand, C. Gascuel-Odoux, P. Mérot, C. Walter, and A. Taha (1998), Hydromorphic soils, hydrology and water quality: Spatial distribution and functional modelling at different scales, Nutrient Cycling Agroecosyst., 50, $127-142$.

Dunne, T., and R. D. Black (1970), An experimental investigation of runoff production in permeable soils, Water Resour. Res., 6, 478-490.

Ellenberg, H. (1991), Zeigerwerte von Pflanzen in Mitteleuropa, 248 pp., Goltze, Göttingen, Germany.

Endreny, T. A., E. F. Wood, and D. P. Lettenmaier (2000), Satellite-derived digital elevation model accuracy: Hydrogeomorphological analysis requirements, Hydrol. Processes, 14(1), 1-20.

Entekhabi, D., I. Rodriguez-Iturbe, and F. Castelli (1996), Mutual interaction of soil moisture state and atmospheric processes, J. Hydrol., 184, $3-$ 17 .

Forstliche Versuchsanstalt (FVA) (1996), Standortskarte des Forstbezirks Kirchzarten, scale 1:10,000, Freiburg, Germany.

Franks, S. W., P. Gineste, K. J. Beven, and P. Merot (1998), On constraining the predictions of a distributed model: The incorporation of fuzzy estimates of saturated areas into the calibration process, Water Resour. Res. 34(4), 787-797.

Freeman, T. G. (1991), Calculating catchment area with divergent flow based on a regular grid, Comput. Geosci., 17, 413-422.

Freer, J., J. McDonnell, K. J. Beven, D. Brammer, D. Burns, R. Hooper, and C. Kendal (1997), Topographic controls on subsurface stormflow at the hillslope scale for two hydrologically distinct small catchments, Hydrol. Processes, 11(9), 1347-1352.

Geologisches Landesamt Baden-Württemberg (GLA) (1977), Geologische Karte von Freiburg im Breisgau und Umgebung, scale 1:50,000, Stuttgart, Germany.
Geologisches Landesamt Baden-Württemberg (GLA) (1981), Erläuterungen zur Geologischen Karte von Freiburg im Breisgau und Umgebung, Stuttgart, Germany.

Gineste, P., C. Puech, and P. Merot (1998), Radar remote sensing of the source areas from the Coet-Dan catchment, Hydrol. Processes, 12, $267-$ 284.

Gómez-Plaza, A., M. Martínez-Mena, J. Albaladejo, and V. M. Castillo (2001), Factors regulating spatial distribution of soil water content in small semiarid catchments, J. Hydrol., 253, 211-226.

Grayson, R., and G. Blöschl (2001), Spatial modelling of catchment dynamics, in Spatial Patterns in Catchment Hydrology: Observations and Modelling, edited by R. Grayson and G. Blöschl, pp. 51-81, Cambridge Univ. Press, New York.

Grayson, R. B., A. W. Western, F. H. Chiew, and G. Blöschl (1997), Preferred states in spatial soil moisture patterns: Local and nonlocal controls, Water Resour: Res., 33(12), 2897-2908.

Güntner, A., S. Uhlenbrook, J. Seibert, and C. Leibundgut (1999), Estimation of saturation excess overland flow areas-Comparison of topographic index calculations with field mapping, in Regionalization in Hydrology, edited by B. Diekkrüger, M. Kirkby, and U. Schröder, IAHS Publ., 254, 203-210.

Gustafson, E. J. (1998), Quantifying landscape spatial pattern: What is the state of the art?, Ecosystems, 1, 143-156.

Hädrich, F., W. Moll, K. Stahr, and K. Böden (1979), Böden, in Exkursionsführer zur Jahrestagung der Deutschen Bodenkundlichen Gesellschaft, Mitt. Dtsch. Bodenkundlichen Ges., vol. 28, edited by H. W. Zöttl, pp. 55-81, Dtsch. Bodenkundliche Ges., Oldenburg, Germany.

Hagen, A. (2003), Fuzzy set approach to assessing similarity of categorical maps, Int. J. Geogr. Inf. Sci., 17(3), 235-249.

Haines-Young, R., and M. Chopping (1996), Quantifying landscape structure: A review of landscape indices and their application to forested landscapes, Prog. Phys. Geogr., 20(4), 418-445.

Hjerdt, K. N., J. J. McDonnell, J. Seibert, and A. Rodhe (2004), A new topographic index to quantify downslope controls on local drainage, Water Resour. Res., 40, W05602, doi:10.1029/2004WR003130.

Hoeg, S., S. Uhlenbrook, and C. Leibundgut (2002), Hydrograph separation in a mountainous catchment-Combining hydrochemical and isotopic traces, Hydrol. Processes, 13(11), 1603-1620.

Holmgren, P. (1994), Multiple flow direction algorithms for runoff modelling in grid based elevation models: An empirical evaluation, Hydrol. Processes, 8, 327-334.

Houser, P., D. Goodrich, and K. Syed (2001), Runoff, precipitation, and soil moisture at walnut Gulch, in Spatial Patterns in Catchment Hydrology: Observations and Modelling, edited by R. Grayson and G. Blöschl, pp. 125-157, Cambridge Univ. Press, New York.

Kirkby, M. (1975), Hydrograph modelling strategies, in Processes in Physical and Human Geography, edited by R. Peel, M. Chisholm, and P. Haggett, pp. 69-90, Butterworth-Heinemann, Woburn, Mass.

Lea, N. L. (1992), An aspect driven kinematic routing algorithm, in Overland Flow: Hydraulics and Erosion Mechanisms, edited by A. J. Parsons and A. D. Abrahams, Chapman and Hall, New York.

Landesamt für Geologie, Rohstoffe und Bergbau Baden Württemberg (1998), Bodenübersichtskarte von Baden-Württemberg, Freiburg, Germany.

Mehlhorn, J., F. Armbruster, S. Uhlenbrook, and C. Leibundgut (1998), Determination of the geomorphological instantaneous unit hydrograph using tracer experiments in a headwater basin, IAHS Publ., 248, $327-$ 336.

Mengelkamp, H.-T., K. Warrach, and G. Kiely (2001), Simulation of hydrological processes with the atmospheric land-surface scheme SEWAB, in Runoff Generation and Implications for River Basin Modelling, Freiburger Schriften Hydrol., vol. 13, edited by C. Leibundgut, S. Uhlenbrook, and J. McDonnell, pp. 243-248, Univ. of Freiburg, Freiburg, Germany.

Moore, I. D., G. J. Burch, and D. H. Mackenzie (1988), Topographic effects on the distribution of surface soil water and the location of ephemeral gullies, Trans. ASAE, 31, 1098-1107.

Moore, I. D., R. B. Grayson, and A. R. Ladson (1991), Digital terrain modeling-A review of hydrological, geomorphological, and biological applications, Hydrol. Processes, 5(1), 3-30.

Nyberg, L. (1996), Spatial variability of soil water content in the covered catchment at Gårdsjön, Sweden, Hydrol. Processes, 10, 89-103.

O'Callaghan, J. F., and D. M. Mark (1984), The extraction of drainage networks from digital elevation data, Comput. Vision Graphics Image Process., 28, 324-344.

O’Loughlin, E. M. (1986), Prediction of saturation zones in natural catchments by topographic analysis, Water Resour. Res., 22, 794-804. 
Patton, D. R. (1975), A diversity index for quantifying habitat edge, Wildlife Soc. Bull., 3, 171-173.

Pontius, R. G. (2000), Quantification error versus location error in comparison of categoral data, Photogramm. Eng. Remote Sens., 66(8), $1011-$ 1016.

Quinn, P. F., and K. J. Beven (1993), Spatial and temporal predictions of soil moisture dynamics, runoff variable source areas and evapotranspiration for Plynlimon, mid-Wales, Hydrol Processes, 7(4), 425-448.

Quinn, P. F., K. J. Beven, P. Chevallier, and O. Planchon (1991), The prediction of hillslope flow paths for distributed hydrological modelling using digital terrain models, Hydrol. Processes, 5, 59-79.

Quinn, P. F., K. J. Beven, and R. Lamb (1995), The $\ln (\mathrm{a} / \operatorname{tanb})$ index: How to calculate it and how to use it within the TOPMODEL framework, Hydrol. Processes, 9, 161-182

Refsgaard, J. C. (2001), Towards a formal approach to calibration and validation of models using spatial data, in Spatial Patterns in Catchment Hydrology: Observations and Modelling, edited by R. Grayson and G. Blöschl, pp. 329-354, Cambridge Univ. Press, New York.

Rodhe, A., and J. Seibert (1999), Wetland occurrence in relation to topography - A test of topographic indices as moisture indicators, Agric. For. Meteorol., 98-99, 325-340.

Saura, S., and J. Martínez-Millán (2001), Sensitivity of landscape pattern metrics to map spatial extent, Photogramm. Eng. Remote Sens., 67(9), $1027-1036$

Scherrer, S., and F. Naef (2003), A decision scheme to indicate dominant hydrological flow processes on temperate grassland, Hydrol. Processes, 17(2), 391-402.

Tarboton, D. G. (1997), A new method for determination of flow directions and upslope area in grid digital elevation models, Water Resour. Res., 33(2), 309-319.

Troch, F. P., N. Verhoest, P. Gineste, C. Paniconi and P. Mérot (2001), Variable source areas, soil moisture and active microwave observations at Zwalmbeek and Coet-Dan, in Spatial Patterns in Catchment Hydrology: Observations and Modelling, edited by R. Grayson and G. Blöschl, pp. 187-208, Cambridge Univ. Press, New York.

Uhlenbrook, S. (1999), Untersuchung und Modellierung der Abflussbildung in einem mesoskaligen Einzugsgebiet, Freiburger Schriften Hydrol., vol. 10, Inst. of Hydrol., Univ. of Freiburg, Freiburg, Germany.

Uhlenbrook, S. (2003), An empirical approach for delineating spatial units with the same dominating runoff generation processes, Phys. Chem. Earth, 28(6-7), 297-303.
Uhlenbrook, S., M. Frey, C. Leibundgut, and P. Maloszewski (2002), Hydrograph separation in a mesoscale mountainous basin at event and seasonal timescales, Water Resour. Res., 38(6), 1096, doi:10.1029/ 2001WR000938.

Uhlenbrook, S., J. Didszun, and C. Leibundgut (2004a), Runoff generation processes on hillslopes and their susceptibility to global change, in Global Change and Mountain Regions: A State of Knowledge Overview. Advances in Global Change Research, edited by U. M. Huber, M. A Reasoner, and B. Bugmann, Kluwer Acad., Norwell, Mass., in press.

Uhlenbrook, S., S. Roser, and N. Tilch (2004b), Hydrological process representation at the meso-scale: The potential of a distributed, conceptual catchment model, J. Hydrol, in press.

Vertessy, R. A., and H. Elsenbeer (1999), Distributed modeling of storm flow generation in an Amazonian rain forest catchment: Effects of model parameterization, Water Resour. Res., 35(7), 2173-2187.

Western, A., and R. Grayson (2001), Soil moisture and runoff processes at Tarrawarra, in Spatial Patterns in Catchment Hydrology: Observations and Modelling, edited by R. Grayson and G. Blöschl, pp. 209-246, Cambridge Univ. Press, New York.

Western, A. W., R. B. Grayson, G. Blöschl, G. R. Willgoose, and T. A. McMahon (1999), Observed spatial organization of soil moisture and its relation to terrain indices, Water Resour. Res., 35(3), 797-810.

Williams, A. G., J. L. Ternan, C. Fitzjohn, S. de Alba, and A. PerezGonzalez (2003), Soil moisture variability and land use in a seasonally arid environment, Hydrol. Processes, 17(2), 225-236.

Wood, J. D. (1996), The geomorphological characterisation of digital elevation models, Ph.D. thesis, Univ. of Leicester, Leicester, U. K.

Zevenbergen, L. W., and C. R. Thorne (1987), Quantitative analysis of land surface topography, Earth Surf. Processes Landforms, 12, 47-56.

A. Güntner, GeoForschungsZentrum Potsdam (GFZ), Telegrafenberg, D-14473 Potsdam, Germany. (guentner@gfz-potsdam.de)

J. Seibert, Department of Environmental Assessment, Swedish University of Agricultural Sciences, Box 7050, SE-750 07 Uppsala, Sweden. (jan.seibert@ma.slu.se)

S. Uhlenbrook, University of Freiburg, Institute of Hydrology, Fahnenbergplatz, D-79098 Freiburg, Germany. (stefan.uhlenbrook@ hydrology.uni-freiburg.de) 